\section{UNA CARTA DE JARDIEL PONCELA A PROPÓSITO DE LA VERSIÓN CINEMATOGRÁFICA DE “LAS INQUIETUDES DE SHANTI ANDIA" POR ARTURO RUIZ CASTILLO}

\author{
Javier Herrera \\ Filmoteca Española. Biblioteca, Archivo Gráfico, Fototeca \\ Magdalena, 10 \\ 28012 Madrid \\ javier.herrera@mcu.es
}

\section{JARDIEL PONCELA'S LETTER ABOUT THE CONEMATOGRAPHIC VERSION OF LAS INQUIETUDES DE SHANTI ANDIA, BY ARTURO RUIZ CASTILLO}

\begin{abstract}
On the occasion of the premiere of Las inquietudes de Shanti Andia realized by Arturo Ruiz Castillo from Baroja's homonymous novel, Jardiel Poncela writes an extensive letter to him, totally unpublished. It is possible to read in it considerations of great interest to know his aesthetic thought and his ideas about public, the role of the women, praises about the adaptation realized from the original novel, as well as interesting considerations on the relations between literature and cinema.
\end{abstract}

KEY WORDS: Public in theatre and cinema; Pio Baroja; Enrique Jardiel Poncela; Arturo Ruiz Castillo; misogyny; literary adaptation (novel); theatre and film critic; aesthetic eclecticism.

Entre los papeles que en su día adquirió la Filmoteca Española a los herederos de Arturo Ruiz Castillo (19101994) se encuentra una extensa e importante carta de Enrique Jardiel Poncela (1901-1952) dirigida al cineasta tras el estreno de su versión de Las inquietudes de Shanti Andía (1947), su primer largometraje. Dicha carta, densa y prolija como todas las suyas (que reproducimos integra al final), con esa caligrafía tan pulcra y concentrada que le caracterizaba, escrita desde el "afecto, la estimación artística, el compañerismo y la buena fe" y en la época en que comienza su definitivo declive físico y creativo', puede considerarse una extraordinaria sintesis de sus ideas respecto a la crítica, el cine, el dinero, el público, el arte y el artista, es decir, todas aquellas cuestiones que le preocuparon -y hasta le obsesionaron- durante su corta pero intensa vida. Nuestra intención es ir desgranando cada una de esas ideas para contribuir a sentar las bases de su pensamiento estético, hasta ahora circunscrito casi
RESUMEN: Con motivo del estreno de Las inquietudes de Shanti Andia realizada por Arturo Ruiz Castillo a partir de la obra de Baroja, Jardiel Poncela le escribe una extensa carta, totalmente inédita, en la que, entre otras consideraciones de gran interés para conocer su pensamiento estético y sus ideas acerca del público y el papel de la mujer, le elogia la adaptación realizada de la obra barojiana al tiempo que le hace una serie de consideraciones teóricas muy interesantes sobre las relaciones entre la literatura y el cine.

PALABRAS CLAVE: Público en el teatro y en el cine; Pío Baroja; Enrique Jardiel Poncela; Arturo Ruiz Castillo; misoginia; adaptaciones literarias (novela); critica de teatro y de cine; eclecticismo estético.

en exclusiva a su teoría y práctica del humor -preferentemente en el teatro- dentro del contexto de la generación del 27 a la que pertenece ${ }^{2}$.

\section{EL CRÍTICO CONTRA EL ARTISTA}

Sabido es que Jardiel fue abominando de la crítica teatral a medida que sus obras eran cada vez más y más inverosímiles, y en esa misma medida incomprendidas, sobre todo, por los críticos afectos al "establishment" político y empresarial durante el franquismo, promotor de gran parte de sus fracasos en esta época a partir del resonante éxito de Los ladrones somos gente honrada (1941), parece ser que, entre otras razones, por su exceso de fidelidad al empresario Tirso Escudero y a su teatro de la Comedia, donde estrenó la mayoría de sus obras ${ }^{3}$. Con tales ante- 
cedentes, es lógico pensar que Jardiel, tras considerar que la reacción de la prensa ante la película "ha estado... frenada, picajosa, llena de reservas y escasa de elogios", empiece por advertir a Ruiz Castillo de la incapacidad de los críticos para saber captar que Las inquietudes..., suponía un caso extraordinario de dominio del oficio cinematográfico dentro de la producción española, y más, teniendo en cuenta que se trataba del primer largometraje de su director; en efecto, Ruiz Castillo, según sus propias declaraciones, había realizado -como guionista, operador y director- hasta ese momento 46 documentales de temáticas preferentemente histórico-artísticas, entre los que se incluyen varios reportajes de guerra, todos ellos para el bando republicano ${ }^{4}$; sin embargo, si bien es cierto que casi ningún crítico destaca ese hecho, no lo es menos que la película de Ruiz Castillo obtuvo una gran repercusión crítica y ni mucho menos en los términos descritos por Jardiel, pues tenemos un amplio abanico de testimonios que nos demuestran lo contrario a pesar de que, como ha señalado Pérez Bowie, para el canon oficialista de la época la recurrencia a un texto literario era garantía de éxito, si bien en el caso de Baroja (como también el de Unamuno con Abel Sánchez, de Serrano de Osma) habría que considerarlo como una asimilación tardía por parte del Régimen al tiempo que un tímido ramalazo aperturista ${ }^{5}$.

La razón de esa falsa apreciación de Jardiel habría que atribuirla a su ofuscación respecto al papel desempeñado por los críticos teatrales -a los que consideraba absolutos ignorantes de la práctica de la literatura escénica- por un lado, así como a la desorientación de un público incapaz en muchas ocasiones de entender la originalidad de las nuevas vías de comicidad que él estaba introduciendo en la escena española ${ }^{6}$. Ésa es la causa por la que establece un paralelismo equívoco entre la crítica teatral y la cinematográfica al objeto de transmitirle a Ruiz Castillo sus ideas sobre el artista y la creación artística:

\footnotetext{
"Pero ya veo -dice- que la crítica de cine es igual que la de teatro -si no es peor- llena de la misma cerrilidad y de idéntica mala fe, por lo cual no tengo que aconsejarte más en ningún momento y te digan lo que te digan (sic), hagas el menor caso de esos cretinos específicos, incapaces de estimar nada ni de proclamar su estimación, porque también son incapaces de crear por su parte".
}

Una advertencia que encaja perfectamente con su maximalismo individualista y ultra-romántico, ligado al concepto de originalidad de raíz wildeana y su rechazo de todo tipo de influencia y contaminación?

"Estate a un lado, impermeable -prosigue- a todo cuanto leas o te digan, y no te apoyes más que en ti mismo, ni invites a nadie a resolverte tus dudas; aún más: no le confieses tus dudas a nadie, y resuélvetelas por tu propio criterio y aplicando a la duda una metodología severa. La opinión ajena te despistará, en lugar de encauzarte: siempre y en todo caso (sic)".

Ensimismamiento, apartamiento del mundo y consiguiente soledad que constituyen los fundamentos del auténtico artista (y así considera Jardiel a Ruiz Castillo), cuya primera convicción -siguiendo de nuevo a Wilde- es considerar al "arte como la realidad suprema y a la vida como una mera obra de ficción" (Valls, 2001, 46) ${ }^{8}$; de ahí que -si se parte de esa premisa- nadie, absolutamente nadie, pueda interferir en su proceso creativo: sólo se puede confiar en uno mismo y en la "luz propia e interior" de cada uno, recomendación ésta en la que sale a relucir el componente sobrenatural de su personalidad, también muy presente en su obra desde el tratamiento del espiritismo en su primera novela, El plano astral (1922), y una constante que marcó toda su vida?.

\section{EL CINE COMO ARTE APLICADO: LA ADAPTACIÓN DE LA NOVELA BAROJIANA}

Lo que falta ahora por definir es cómo un director de cine puede ser artista o cómo puede casarse a Oscar Wilde con la modernidad representada por la técnica cinematográfica y en el seno de una industria cuyos valores estéticos se miden "por las cifras de lo que produzca".

Para empezar, lanza un generoso elogio de la labor de Ruiz Castillo como director, lo que teniendo en cuenta su experiencia en el medio desde 1931 no deja de ser significativo ${ }^{10}$ :

"La dirección es perfecta; de ritmo, de armonía, de precisión, de concepción y de montaje. Y se advierte, además, clarisima, en el trabajo de los intérpretes, que todos pa- 
recen buenos y yo se que pocos de ellos lo son; así como está igualmente patente en el movimiento -tan justo, tan reducido a lo necesario, que es lo difícil y tan expresivo, sin embargo- de la cámara. La fotografía es buena también; y en algunos momentos, como en el cementerio, magnifica".

Como se ve, unas consideraciones que no por generosas, en este caso dejan de ser acertadas, pues en el resultado final de la película el oficio anterior de Ruiz Castillo se nota. Sin embargo, el auténtico problema del cine como "arte aplicado" -o "arte cotizable" como más adelante lo califica- reside, al igual que en el teatro, en el éxito de público, en el dinero que proporcione; y es ahí donde Jardiel habla de su admirado Baroja, haciéndole prácticamente responsable de que la película pudiera ser un fracaso económico:

"La película, en mi opinión -pronostica Jardiel- no va a dar dinero. Ojalá me equivoque, pero creo que no me equivocaré... porque si el Shanti no da dinero no será por culpa de Ruiz Castillo sino por culpa del Shanti. Trabajando para el público hay que conservar siempre la frialdad de juicio bastante para saber cuándo se ha equivocado uno y cuándo la equivocación es de otro... Si el Shanti no da dinero la culpa es de Baroja; esto es: de la novela; esto es de la historia elegida para la película";

opinión que puede suscribirse en su integridad pues confirma uno de los principios básicos de la adaptación de obras literarias, cual es el de la selección de la obra fuente o matriz por parte del adaptador y la mayor o menor fidelidad respecto a ella: tiene razón Jardiel en el hecho de que si la "historia" elegida no es buena, el resultado final se resiente y puede ser un fracaso; sin embargo, aquí Jardiel pretende exculpar de su responsabilidad en la elección a Ruiz Castillo insistiendo en la "culpabilidad" de la novela barojiana, apreciación que no resulta acertada por cuanto que, en primera instancia, el acierto en la elección depende de quien elige y no del elegido, y en segundo lugar, también depende por lógica de cómo se efectúe la transposición de un medio a otro y de los recursos técnicos empleados para que la película obtenga el éxito deseado. En este sentido, la película fue un acierto pues la crítica por unanimidad señaló este respeto al mundo barojiano y su acertada transposición cinematográfica. Valgan como muestra estos ejemplos:
"El relato de Baroja encuentra una fiel traducción en imágenes. Brilla una plástica de excelente concepto poético bien captada desde encuadres que acusan sentido del cine y buen gusto en la composición de la escena. Ruiz-Castillo mantiene el ritmo y el estilo adecuado a la narración sin un solo desmayo, ceñido a la línea barojiana, acudiendo por derecho a la situación para resolverla con dominio de la técnica..." (Sánchez, 1947, s.p.).

"Como en toda obra de Pío Baroja, en esta novela hay varias acciones dentro de la acción general, singularidad del estilo de este escritor que ha sido certeramente reflejado por el director Arturo Ruiz-Castillo" (Anónimo, 1947b, s.p.).

"Lo mejor de esta cinta es el clima. El aguafuerte barojiano -aguafuerte de luces, tipos y reacciones sentimentales- ha sido expresado con exactitud y dureza en la película de Ruiz-Castillo. Se conserva la profundidad ambiental y la reciedumbre opresora de las historias marineras; los escenarios claroscuros y la imponente grandeza del océano. Hasta el denso confusionismo de la trama -trama de tenebrosas historias trenzadas- se ha conservado integramente, sacrificándose en muchos momentos la estructura cinematográfica a un mayor apasionamiento por la obra literaria" (Anónimo, 1947a, s.p.).

Un logro que coincide también con las intenciones del propio autor expresadas en su autocrítica antes del estreno:

"Dicen que Las inquietudes de Shanti Andía es una buena película, que tiene esto y aquello bueno, que es muy barojiana, profundamente española y que tiene belleza, tristeza y sentimentalismo en sus escenas. También dicen que la película tiene 'clima', esa cosa que no se sabe qué es, pero que suena bien, y que yo creo que es puro ambiente literario y artístico; tal como lo concibió Baroja, que para eso es el padre de la criatura. Y yo esta vez me he limitado a hacer su transcripción a la pantalla. Toda la obra de Pío Baroja tiene tanta fuerza que ella sola por sí misma apasiona... Realmente la película responde a su título, y esto en definitiva es mérito de Baroja, de la obra literaria" (Ruiz-Castillo, 1947, s.p.).

Aunque ese exceso de protección en el prestigio de Baroja y de seguidismo de su novela también le acarreara alguna crítica menos complaciente, como la publicada en el Boletín del SIPE:

"La novela, múltiple dentro de una unidad general de acción, ha influido poderosamente en la realización de la

ARBOR Vol. 187748 marzo-abril [2011] 287-303 ISSN: 0210-1963 
película, con su ambiente y sus tipos fuertes, que han sido recogidos con acierto. En cambio, la excesiva fidelidad del guión y unos diálogos demasiado literarios le dan cierta morosidad que perjudica la agilidad de su desarrollo y a veces parece romper la unidad de la trama" (Anónimo, 1947 c, s.p.).

0 esta otra de Miguel Pérez Ferrero que, en nuestra opinión, acierta al expresar alguno de los problemas de RuizCastillo a la hora de adaptar la novela barojiana:

\begin{abstract}
"Para un realizador cinematográfico, encararse con una novela grande, densa de acción, de acontecimientos, de tipos, plantea el problema de condensación, lo cual es sumamente difícil cuando el tema es tan rico e interesante, que se quisiera aprovechar por entero. Aquí Ruiz-Castillo tenía que resolver y decidir el sacar como acción principal la historia de Juan de Aguirre, verdadero nudo de la novela, o seguir exactamente la línea de ésta. Se inclinó por lo último. Y a ello se debe el que, quizá, su "film" sea excesivamente narrativo, en el sentido de que cuentan cosas los personajes que no se ven en la pantalla. En una novela, esto no importa porque la fantasía del lector ve en la imaginación las escenas relatadas por cualquiera de los tipos, mientras que el espectador cinematográfico queda prendido preferentemente en lo visual que se le sirve" (M.P.F., 1947, s.p.).
\end{abstract}

Efectivamente, esa era la disyuntiva que tenía ante sí Ruiz-Castillo: centrarse o no exclusivamente en la historia de Juan de Aguirre, una cuestión que va directamente relacionada con la "condensación" argumental de que habla Pérez Ferrero pues, ciertamente, Ruiz-Castillo elimina muchos pasajes y personajes, así como resume información (sobre todo de tono descriptivo y ambiental, admirablemente resuelta su riqueza literaria con los decorados y los exteriores), pero sigue conservando en cierto modo la línea argumental, si bien hay que considerar un poco baladí el planteamiento de Pérez Ferrero, pues tanto en la novela como en la película el nudo gordiano lo constituye el misterio de la desaparición y posterior encuentro de Juan de Aguirre: la diferencia radica en que acaso Ruiz-Castillo -y ahi es donde estaría más justificada la crítica de Pérez Ferrero- da algunos rodeos en torno a dicho nudo que ralentizan inevitablemente -consecuencias de la condensación temporal- la narración fílmica.

\section{EL PÚBLICO, LA MUJER Y EL DINERO}

El caso es que los malos augurios de Jardiel sólo se cumplieron en parte pues a la aceptable recepción crítica se unió una buena pero escasa acogida por parte del público, que no impidió a Ruiz-Castillo y a su socio, Alberto Álvarez de Cienfuegos, seguir realizando aún dos películas más dentro de la línea iniciada con Las inquietudes..., una combinación entre el melodrama romántico y género de aventuras: Obsesión (1947) y La manigua sin Dios (1948)"1.

Volviendo a Jardiel, no deja de ser curioso, a la par que interesante y discutible, su razonamiento acerca del posible fracaso económico de la película al considerar que la obra en general de Baroja no le gusta al público porque el "público" lo forman las "mujeres", y como Baroja no gusta a las mujeres, no hay éxito económico que valga:

"Porque (y no hay que decir cuánto me gusta a mí Baroja
y cómo le admiro) Baroja, en general, no gusta al público,
porque no les gusta a las mujeres y no se debe olvidar tam-
poco que el público (igual el masculino que el femenino)
lo forman las mujeres, ya personalmente, ya arrastrando al
hombre tras sí. En arte cotizable nada que no guste a las
mujeres da dinero; y a la inversa, todo lo que gusta a las mu-
jeres da dinero. Hablo, naturalmente, de la mujer corriente,
no la seleccionada, que es una minoría inapreciable".

Tampoco en esto le falta razón a pesar de que exagera un tanto pues creemos que, una vez más, extrapola su experiencia del mundo teatral al cinematográfico y, si bien es cierto que respecto al teatro podría hablarse de una caracterización más femenina del público, no lo es en lo tocante al cine si nos atenemos a los aspectos cuantitativos $^{12}$. No parece, pues, que la consideración de Jardiel sobre el protagonismo exclusivo de la mujer en la conformación del público receptor de películas haya tenido una gran influencia en el escaso éxito de Las inquietudes..., si bien en lo que respecta al "gusto" femenino en relación con Baroja, sí puede caber alguna animadversión debido a su fama de misógino y demás facetas de su carácter, no demasiado simpáticas, no sólo para las mujeres, sino para el resto de ciudadanos; sin embargo, las razones profundas que da Jardiel son distintas y de mayor calado teórico, amén de que no contribuyen en nada a difuminar la etiqueta de misógino que le persigue desde siempre. Son estas: 
"Y no hay que olvidar tampoco -prosigue- que eso de que la mujer es la sensibilidad es mentira (sic). La sensibilidad lo es el hombre. La mujer -siempre en general- es muy bruta y tan extraordinariamente poco sensible que sólo reacciona de veras (sic) ante los sentimientos o pasiones muy burdos, muy elementales, muy reales: ejemplo, por todos, la maternidad. Pero lo sutil, lo insinuado, el matiz, la sugerencia -todo $\underline{\text { lo }}$ fino (sic) en suma- es masculino y anti-femenino y le resulta ingrato a la mujer. Baroja -lo mismo en el Shanti (sic) que en sus demás libros- no maneja nunca los sentimientos elementales, y si los maneja, al manipular con ellos, los transforma y les priva -refinándolos- de su elementalidad. Naturalmente, a las mujeres no les gusta Baroja y no les gustará, seguramente, el Shanti, en el que tu has conservado, con extraordinaria pureza, toda la finura de Baroja, y al no gustarle a las mujeres no dará dinero. También a las mujeres (y al público en general por tanto) les repugna lo original, pues lo original es -por esencia- antifemenino: y Baroja, en el Shanti y en todo, es original".

Como vemos, el razonamiento de Jardiel se basa en tres silogismos sui generis que él cree verdaderos por ser-como dice más adelante- "la esencia decantada de la observación y el análisis" y que, sin embargo, carecen de lógica tal y como vemos a continuación:

1 (SI) El gusto de las mujeres es el gusto del público y el público supone dinero

(SI) Baroja no gusta a las mujeres

= Baroja no da dinero

2 (SI) Las mujeres son poco sensibles y la finura y la originalidad son antifemeninas

(SI) Baroja es sensibilidad, finura y originalidad

= Baroja no gusta a las mujeres

3 (SI) Baroja no gusta a las mujeres

y Shanti-Andía es una obra de Baroja y una película basada en la obra de Baroja

= la película Shanti-Andía no gustará a las mujeres y no dará dinero

En efecto, se trata de un razonamiento ilógico -lo que se llama "silogismo hipotético"- que al partir de asertos condicionales (es decir posibles pero falaces, aunque Jardiel los considere verdaderos) que mezclan una ecuación posible pero improbable que relaciona el gusto y el éxito econó- mico (gusto de mujeres=gusto del público=dinero), juicios subjetivos muy discutibles (los hombres son la sensibilidad y la finura, la mujer sólo reacciona ante sentimientos elementales), juicios literarios y estéticos certeros (la originalidad de Baroja) y una sola verdad incuestionable (ShantiAndía como obra de Baroja y película), su resultado final puede ser falso o todo lo más harto improbable, pues el factor común es que Baroja y las mujeres son totalmente incompatibles; es más, a pesar de todas las combinaciones que pudieran hacerse con las mismas premisas, siempre se obtendría la misma conclusión: que la película será un fracaso económico pero el culpable no será su director, Ruiz-Castillo, sino Baroja por ser autor de la novela original $y$, en última instancia, las mujeres por no gustarles Baroja y constituir su gusto el del público en general; es decir: cualquier razonamiento con tal de eximir de su responsabilidad al hijo de su gran amigo.

Notemos que a medida que vamos avanzando en la lectura de la carta, comprobamos que el pensamiento estético y las teorías artísticas de Jardiel se van concretando y aclarando, a la par que se manifiestan muchos aspectos de su vida personal, de su trayectoria profesional $y$, sobre todo, del espíritu, el contenido y la forma de sus obras.

Así, por ejemplo, respecto al fracaso económico de la película actúa como si fuera un adivino capaz de conocer el porvenir, utilizando para ello tanto la creencia y el temor mezclados en forma negativa: "no va a dar", como el futuro imperfecto igualmente negativo: "no dará"; una manifestación más de su interés por lo esotérico y paranormal, a su vez conectado con la poética de lo inverosímil sobre la que gira tanto su original obra literaria como su creatividad. Dicha inverosimilitud -"sólo lo inverosímil -dirá- me atrae y me subyuga; de tal suerte, que lo que hay de verosímil en mis obras lo he construido siempre como concesión y con repugnancia" (Valls, 2001, 66)- se manifiesta en la carta que comentamos en el regusto por invertir la opinión comúnmente aceptada y la lógica habitual del discurso: si lo normal es considerar la sensibilidad como una cualidad femenina, para él es mentira, es del hombre; si también se le suelen asociar la sutileza, la insinuación, el matiz, la sugerencia, todo lo fino, para él son cualidades masculinas; así, de ese modo, sobre la inversión de lo habitual y lo aceptado socialmente, es decir de lo vulgar -amén del uso de silogismos falaces- va edificando su discurso antifemenino que es también una teoría anti-realista del arte

ARBOR Vol. 187748 marzo-abril [2011] 287-303 ISSN: 0210-1963 
y de la realidad pues es la mujer quien domina ese terreno con sus pasiones y sentimientos burdos, elementales y "reales"; es decir un discurso muy wildeano, muy esnobista y aristocratizante, que es más -creemos- una pose estética, verdadera e inequívocamente machista, ciertamente, que una auténtica y sincera misoginia, actitud que choca frontalmente con la mentalidad "moderna" y abierta del feminismo vanguardista de su época.

\section{Teoría del "gusto" medio y eClecticismo estético}

Dicha inversión del discurso habitual y el componente anti-realista de su poética centrada en el humor, se encuentra cercana a la actitud surrealista, tal y como él mismo apuntara en alguna ocasión, aunque sin conciencia plena de lo que significaba ese movimiento: "Valía la pena de explicar -dice en el prólogo a Madre (el drama padre)cómo el arte del humorismo confina, en lo grotesco y funambulesco, con lo trágico del delirio, con el sueño y las vaguedades y explosiones de la alucinación" (Valls, $2001,62)$. Efectivamente, la no aceptación de la realidad tal cual es para trascenderla y darle otra dimensión no habitual, está en la base de una poética que pretendia "fuera entendida por todos y que atrajera a todos" (Valls, 2001, 65), al igual que en su momento Tirso, Calderón y Lope lo consiguieron; pretensión que chocaba una y otra vez con la realidad de un público -como ya hemos visto dominado por el gusto femenino- que sólo atendía a lo razonable y lo que sucede a ras de tierra, incapaz de caer en la ensoñación o en brazos de la poesía. Sin embargo, esa era la realidad con la que había que contar y a la que había que adaptarse, hecho que plantea a Jardiel no pocas dudas acerca de las concesiones que debía hacer a ese público que detestaba pero del que tenía que vivir, dudas que le transmite a Ruiz-Castillo en el tercer bloque de la carta:
¿¿Cuál es -se pregunta- el rumbo para un artista? ¿Seguir el criterio del público -lo femenino- o seguir su propio y refinado criterio? Lo primero da el éxito de dinero y la consideración social; lo segundo no da el éxito de dinero y rara vez conduce más que a la consideración artística, pero -en todo caso- sólo conduce a ella".

La solución que aventura es consecuente con todos sus razonamientos anteriores que -recordemos- mezclaban todo tipo de premisas y que según nuestro entender esboza lo que podríamos denominar una teoría del gusto medio:

"La solución es lo intermedio: mezclar los dos criterios en dosis hábiles (sic). Ese es, a mi juicio, tu camino. Yo lo he seguido con evidente resultado favorable. $Y$ en esa mezcla tienen que darse juntos -por ejemplo- lo fino y lo basto; lo sugerido y lo patente; lo real y la ensoñación; lo noble y lo vil; lo original y lo manoseado, etc., etc... Sólo mezclando los dos criterios puede lograr los éxitos de dinero el artista; y aún así si la mezcla falla en las dosis: más vileza que idealismo o más idealismo que vileza; si es superior la dosis de criterio artístico (sic) a la dosis de criterio público (sic), también falla el éxito económico... Naturalmente cuál ha de ser la dosificación exacta en cada caso es ciencia infusa, pues no hay reglas para ello, y de ahí que el acertar siempre (sic) tampoco se produce con la mencionada fórmula de mezcla de los dos criterios, pero si no se produce siempre (sic), al menos se tiene la seguridad de conseguirlo muchas veces (sic)",

teoría que conduce inexorablemente a un eclecticismo estético coincidente en su totalidad con la ideología que profesó y que él mismo resume así: "Jamás he sido un hombre de derechas o de izquierdas. Me gustaron siempre las ideas inherentes a los dos bandos y con su mezcla estaba hecha mi ideología ecléctica" (Valls, 2001, 48).

\section{NOTAS}

1 La carta está escrita el 6 de febrero de 1947 tras el logro del Premio

Recibido: 21 de octubre de 2008

Aceptado: 23 de marzo de 2009
Nacional de Teatro por El sexo débil ha hecho gimnasia y el fracaso de
Como mejor están las rubias es con patatas, una época en la que, en el decir de su biógrafo, Rafael Flórez, se encontraba "herido" y se le notaba en el trato general "cierta irascibilidad, una irritabilidad progresiva que 
es posible que en ciertos aspectos le fueran a convertir en insoportable" (Flórez, 1993, 320).

2 Véase Conde Guerri (1981), Cuevas (ed.) y Baena (coord.) (1993), Escudero (1981) y Sánchez Castro (2007).

3 Véase Flórez, 1993: 329-336.

4 Transcripción escrita del programa de la Cadena SER "Personajes del día. D. Arturo Ruiz Castillo". Entrevista de Donaciano Aragón Asenjo, 7 de febrero de 1947.

5 Véase Pérez Bowie, 2004, 123.

6 "Los críticos, aun los que poseen una cultura teatral, ignoran en absoluto la práctica de la literatura escénica" (Valls y Roas, 2001, 29-30).

7 He aquí la cita más famosa de Wilde sobre las influencias: "No hay influencia buena; toda influencia es inmoral, inmoral desde el punto de vista científico. Influir sobre una persona es transmitirle nuestra propia alma" (http://es.wikiquote. org/wiki/Oscar_Wilde. Consultada el 13/11/2008).

8 Citado por Valls, 2001, 46. Según estos autores Oscar Wilde proporciona a Jardiel Poncela el modelo estético; en cualquier caso es un tema en el que convendría profundizar.

9 Véase Evangelina Jardiel Poncela (1999). Son numerosos los hechos "sobrenaturales" que relata, sobre todo, los relacionados con las frecuentes visitas que realizaba a la tumba de su madre, enterrada en la localidad aragonesa de procedencia, cada vez que tenía algún grave problema.

10 Para la relación de Jardiel Poncela con el cine véase Fernández Cuenca, 1952, 39-42, Torres Nebrera, 1993, 227-258, Garcia Fuentes, 1994, 105 118, Heinink, 2002, 10-13, Fernández Colorado, 2002, 14-25, y Díez Puertas, 2002, 153-170.
$11 \mathrm{Su}$ productor Alberto Álvarez de Cienfuegos declararia: "Desde luego estamos muy contentos con nuestro primer hijo, que es Las inquietudes de Shanti-Andía, que ha gustado de verdad a los pocos que la han visto y que nos han pedido para siete países extranjeros en muy buenas condiciones" (Garcia, 1947, s.p.).

12 Aunque no tenemos datos de la época fiables respecto a la asistencia al cine según los sexos, sí los tenemos de unos veinte años después, lo que nos puede dar una idea aproximada: "Los hombres van más al cine que las mujeres: el $30 \%$ dicen haberlo hecho durante las cuatro últimas semanas y las mujeres, en cambio, el $27 \%$, aunque bien se puede afirmar que las diferencias porcentuales no son importantes y en realidad mantienen una asiduidad similar a la de los hombres" (Instituto de la Opinión Pública, 1968, 222).

\section{BIBLIOGRAFÍA}

Anónimo (a) (1947): "Callao: Las inquietudes de Shanti Andia", Arriba, 4 de febrero.

- (b) (1947): Cine-Club del Círculo de Escritores Cinematográficos, 26. ${ }^{\text {a Se- }}$ sión. Cine Colón. Miércoles 29 de enero.

- $\quad$ (c) (1947): "Las inquietudes de Shanti-Andia", Boletín S.I.P.E., 6-13 de febrero.

Conde Guerri, María José (1981): El teatro de Enrique Jardiel Poncela: aproximación crítica, Madrid, Consejo Superior de Investigaciones Científicas.

Cuevas, Cristóbal (ed.) y Enrique Baena (coord.) (1993): Jardiel Poncela: teatro, vanguardia y humor, Málaga, Universidad de Málaga.
Díez Puertas, Emeterio (2002): "Jardiel y el cine", Cuadernos Hispanoamericanos, 625-626, pp. 153-170.

Escudero, Carmen (1981): Nueva aproximación a la dramaturgia de Jardiel Poncela, Murcia, Servicio de Publicaciones de la Universidad de Murcia.

Fernández Cuenca, Carlos (1952): "Enrique Jardiel Poncela y el cine", Servicio de Información Cinematográfica -Brújula del Cine, 199-200, 1 de marzo, pp. 39-42.

Fernández Colorado, Luis (2002): "La escritura silente", Archivos de la Filmoteca, 40, pp. 14-25.

Flórez, Rafael (1993): Mío Jardiel: Jardiel Poncela está debajo de un almendro en flor. Madrid, Alfaquequerías, Biblioteca Mirífica del Autor.

García, Adán (1947): "Charla con Arturo Ruiz-Castillo", Primer Plano, n. ${ }^{\circ} 327$, 19 de enero.

García Fuentes, Enrique (1994): "El cine en la novelistica de Enrique Jardiel Poncela", Notas y estudios filológicos, 9, pp. 105-118.

Heinik, Juan B. (2002): "Jardiel Poncela y el cine: una aproximación en cinco actos", Archivos de la Filmoteca, 40, pp. 10-13.

Instituto de la Opinión Pública (1968): Estudio sobre la situación del cine en España. Madrid, Editora Nacional.

Jardiel Poncela, Evangelina (1999): Enrique Jardiel Poncela: mi padre, Madrid, Biblioteca Nueva, 1999.

M.P.F. (1947): "Callao. Las inquietudes de Shanti-Andia", $A B C, 4$ de febrero.

Pérez Bowie, José Antonio (2004): Cine, literatura y poder. La adaptación cinematográfica durante el primer franquismo (1939-1950), Salamanca, Librería Cervantes.

Ruiz-Castillo, Arturo (1947): "Las inquietudes de Shanti-Andia. Autocrítica", Diario Alcázar, 2 de febrero. 
Sánchez, Alfonso (1947): "Las inquietudes de Shanti Andía, en el Callao", Pueblo, 4 de febrero.

Sánchez Castro, Marta (2007): El humor en los autores de la otra generación del 27:
Análisis lingüístico-contrastivo - Jardiel Poncela, Mihura, López Rubio y Neville, Frankfurt am Main, Peter Lang.

Torres Nebrera, Gregorio (1993): "Teatro y cine en Jardiel: dos ejemplos". En
Cristóbal Cuevas (ed.) y Enrique Baena (coord.), pp. 227-258.

Valls, Fernando y David Roas (2001): Enrique Jardiel Poncela, Madrid, Ediciones Eneida. 


\section{Carta de Enrioue Jardiel Poncela a Arturo Ruiz-Castillo}

[Madrid] 6 de febrero [1947]

\section{Querido Arturo:}

Al fin, no recibí las localidades ofrecidas para el estreno del Shanti, pero fui yo a la noche siguiente, pues ya te figurarás que no quería quedarme sin verla y que, además, tenía prisa por verla. Casi preferí que no me enviaras localidades para el estreno, porque los estrenos no me gustan demasiado, principalmente por la clase de público que va a ellos; pero en cambio sí me hubiera gustado ver la reacción de ese público -siempre un poco envenenado- ante la primera proyección.

Por mi parte, a mí no me defraudó lo más mínimo y cuenta que yo esperaba -como sabes- mucho de ti; o para ser más exacto, esperaba el máximun (sic). De suerte que, al decirte que no me defraudó la película lo más mínimo, te hago el elogio mayor también que yo pueda hacer de una película.

La dirección es perfecta; de ritmo, de armonía, de precisión, de concepción y de montaje. Y se advierte, además, clarísima, en el trabajo de los intérpretes, que todos parecen buenos y yo se que pocos de ellos lo son; así como está igualmente patente en el movimiento -tan justo, tan reducido a lo necesario, que es lo difícil y tan expresivo, sin embargo- de la cámara. La fotografía es buena también; y en algunos momentos, como en el cementerio, magnífica. En suma, a mi juicio, no hay más que pedir... ni más que ofrecer. Pero, como de costumbre, la prensa ha estado, salvo Informaciones (en lo que yo he leído) frenada, picajosa, llena de reservas y escasa de elogios, pues -aparte de los méritos- tu dirección es la primera dirección de un director; y, si no considerando eso, es muy buena, considerándolo es extraordinaria, porque revela lo que en España no se había revelado antes desde que el cine es cine: que se puede dar el caso increíble de que en una primera película un director domine el oficio, cualidad que no es íntima e innata, como el buen gusto o como la inspiración, sino que hay que adquirirla en la práctica. Yo sabía ya que tú tenías oficio, pero los críticos de cine, no; y a ellos, por lo tanto, tu película tenía que producirles mucho más efecto y provocar muchos más entusiasmos. Pero ya veo que la crítica de cine es igual que la de teatro -si no es peor- llena de la misma cerrilidad y de idéntica mala fe, por lo cual no tengo que aconsejarte que en ningún momento y te digan lo que te digan, hagas el menor caso de esos cretinos específicos, incapaces de estimar nada ni de proclamar su estimación, porque también son incapaces de crear por su parte. Estate a un lado, impermeable a todo cuanto leas o te digan, y no te apoyes más que en ti mismo, ni invites a nadie a resolverte tus dudas; aún más: no le confieses tus dudas a nadie, y resuélvetelas por tu propio criterio y aplicando a la duda una metodología severa. La opinión ajena te despistará, en lugar de encauzarte: siempre y en todo caso. 0 se es artista o no se es artista, y cuando se es artista nadie puede resolverle a uno el menor problema, por la sencilla razón de que tampoco son artistas los demás. Tú eres artista y tu camino más seguro es meterte cada vez más en ti mismo, a no esperar otra luz que la propia e interior, que, en definitiva, y salvo eclipses, es la más radiante.

Quizá te extrañe que te diga todo esto, pero decírtelo es casi el exclusivo objeto de esta carta, porque ahora es cuando te precisa oírlo, por ser ahora también cuando, por primera vez, hacer un arte aplicado, esto es: un arte industrializado y que todo el mundo va a medir por las cifras de lo que produzca. Ahora es, a mi juicio, cuando necesitas que alguien -que va algunos años delante andando por ese peligroso camino y que conoce todas las trampas en que el suelo se abre delante del que anda- te traslade esas dos o tres verdades que los demás no pueden decirte porque las ignoran o porque se las reservan. 
La película, en mi opinión, no va a dar dinero. Ojalá me equivoque, pero creo que no me equivocaré, pues ya me conozco bien a los clásicos y los clásicos son, en este caso, los López, Rodríguez, Fernández, etc. que se sientan, después de haber pagado, en las butacas. Si me equivoco, nada. Si no me equivoco, no te desanimes ni un ápice, porque si el Shanti no da dinero no será por culpa de Ruiz Castillo, sino por culpa del Shanti. Trabajando para el público hay que conservar siempre la frialdad de juicio bastante para saber cuándo se ha equivocado uno y cuándo la equivocación es de otro; pues el público, la prensa, los amigos, los compañeros y a veces hasta la propia familia, indefectiblemente, le echan la culpa a uno por creer que es uno quien la tiene. Si el Shanti no da dinero la culpa es de Baroja; esto es: de la novela; esto es de la historia elegida para la película. Porque (y no hay que decir cuánto me gusta a mí Baroja y cómo le admiro) Baroja, en general, no gusta al público, porque no les gusta a las mujeres y no se debe olvidar tampoco que el público (igual el masculino que el femenino) lo forman las mujeres, ya personalmente, ya arrastrando al hombre tras sí. En arte cotizable nada que no guste a las mujeres da dinero; y a la inversa, todo lo que gusta a las mujeres da dinero. Hablo, naturalmente, de la mujer corriente, no la seleccionada, que es una minoria inapreciable. $Y$ no hay que olvidar tampoco que eso de que la mujer es la sensibilidad es mentira. La sensibilidad lo es el hombre. La mujer -siempre en general- es muy bruta y tan extraordinariamente poco sensible que sólo reacciona de veras ante los sentimientos o pasiones muy burdos, muy elementales, muy reales: ejemplo, por todos, la maternidad. Pero lo sutil, lo insinuado, el matiz, la sugerencia -todo lo fino en suma- es masculino y anti-femenino y le resulta ingrato a la mujer. Baroja -lo mismo en el Shanti que en sus demás libros- no maneja nunca los sentimientos elementales, y si los maneja, al manipular con ellos, los transforma y les priva -refinándolos- de su elementalidad. Naturalmente, a las mujeres no les gusta Baroja y no les gustará, seguramente, el Shanti, en el que tú has conservado, con extraordinaria pureza toda la finura de Baroja, y al no gustarle a las mujeres no dará dinero. También a las mujeres (y al público en general por lo tanto) les repugna lo original, pues lo original también es -por esencia- antifemenino: y Baroja, en el Shanti y en todo, es original.

De esto no se puede hablar con nadie, y menos naturalmente con las mujeres, pues el tópico es contrario a cuanto va dicho, pero el falso aquí es el tópico: y además las mujeres se defienden de lo que consideran como un menosprecio humillante cuando no es sino la esencia decantada de la observación y del análisis. Es decir: una profunda verdad, que quien trabaja para el público ni puede ni debe olvidar.

¿Cuál es, pues, el rumbo para un artista? ¿Seguir el criterio del público -femenino- o seguir su propio y refinado criterio? Lo primero da el éxito de dinero y la consideración social; lo segundo no da el éxito de dinero y rara vez conduce más que a la consideración artística, pero -en todo caso- sólo conduce a ella.

La solución es lo intermedio: mezclar los dos criterios en dosis hábiles. Ese es, a mi juicio, tu camino. Yo lo he seguido con evidente resultado favorable. $Y$ en esa mezcla tienen que darse juntos -por ejemplo- lo fino y lo basto; lo sugerido y lo patente; lo real y la ensoñación; lo noble y lo vil; lo original y lo manoseado, etc., etc. Y no dejarse engañar, como suele engañarse la gente, por las apariencias. Siempre que a mí me dice algún despistado de turno (es decir alguna persona corriente) "las comedias de usted gustan por lo originales", yo contesto: "gustan a pesar de lo originales" y entonces el que preguntó suele reirse, creyendo que yo le he gastado una broma; $y$, sin embargo, le he replicado en serio, y trasladándole una profunda verdad: una de las verdades que el autor teatral o el director de cine tiene que tener -si ha de conseguir éxitos- constantemente delante de los ojos.

Sólo mezclando los dos criterios puede lograr los éxitos de dinero el artista; y aún así si la mezcla falla en las dosis: más vileza que idealismo o más idealismo que vileza; si es superior la dosis de criterio artístico a la dosis de criterio público, también falla el éxito económico. Porque el problema -ya en ese caso- ha quedado reducido a un problema de ponderación, de dosificación de producto farmacéutico, y al fallar la dosificación, falla el producto. 
Naturalmente cuál ha de ser la dosificación exacta en cada caso es ciencia infusa, pues no hay reglas para ello, y de ahí el que al acertar siempre tampoco se produce con la mencionada fórmula de mezcla de los dos criterios, pero si no se produce siempre, al menos se tiene asi la seguridad de conseguirlo muchas veces.

En resumen de este largo escrito, que el afecto, la estimación artística, el compañerismo y la buena fe me han movido a enviarte: enhorabuena sincera y entusiasta por el Shanti, pues has hecho con él lo más y lo mejor que con el Shanti puede hacerse -y ánimo y optimismo y confianza en ti mismo si el Shanti no diera dinero, pues no depende de ti ese resultado.

De todas maneras aún me gustaría que charlásemos más si hubiera ocasión. Ya la habrá.

Afecto a los tuyos y un fuerte abrazo de tu amigo que te quiere y admira

\section{E. Jardiel Poncela}

¡Ah! Una cosa que ya se me olvidaba. Aún tendría más emoción la muerte de Aguirre si le dieras un pequeño corte que enlazase el instante en que Shanti y Mary se retiran de la ventana con el momento en que Urbistondo y el Doctor entran en la habitación, suprimiendo el plano intermedio de Mary y Shanti, en el que la Hernán no está feliz de expresión.

Todo lo del barco es espléndido. 


\section{ENRIQUE IARDIEL PONCELA}

\section{6 ge texbedo
gheven}

\section{Puentio Arturo:}

Th lik, no recibs

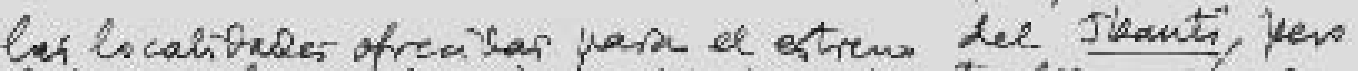

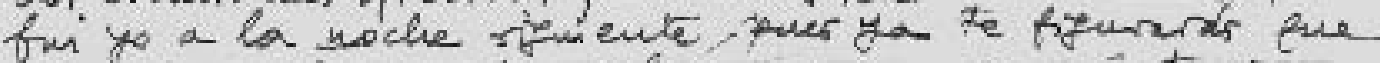

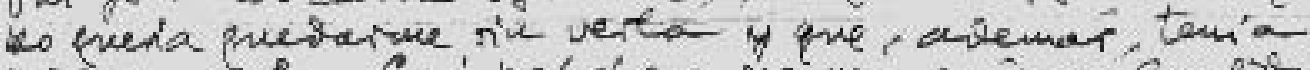

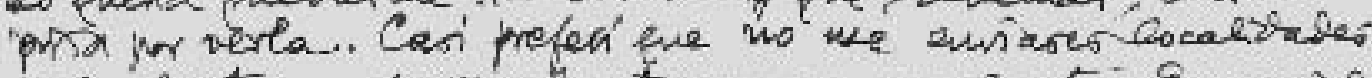

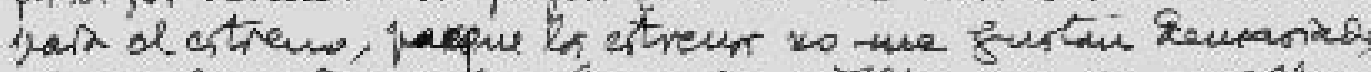
phincipaluent par la clare de priblis tou va a eler:

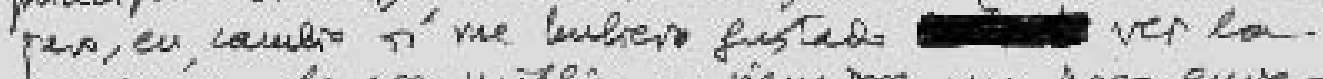
teaceion de are viflito a vien pre we poco evere -

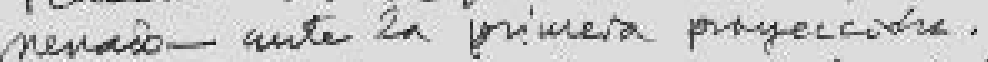

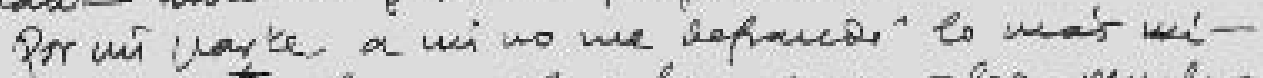

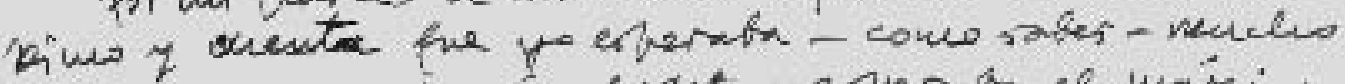
DeX:; o, yara rer was exact espera on el kaxi-

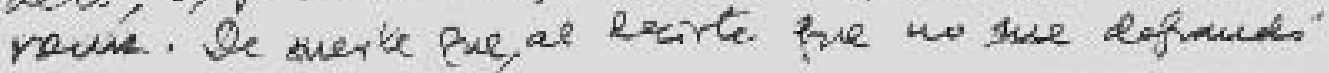




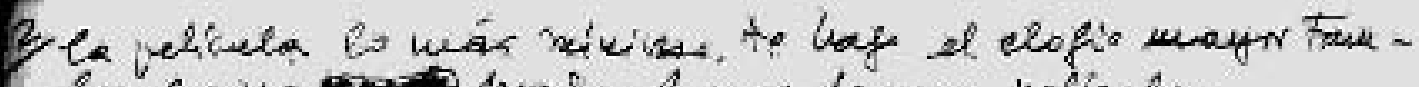

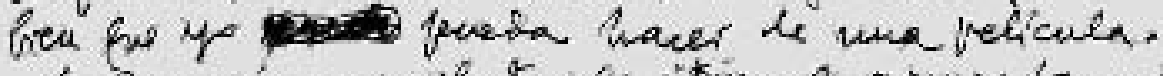

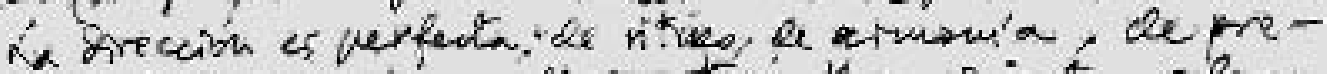

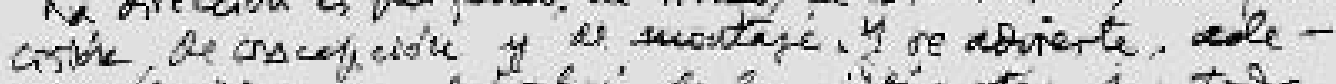

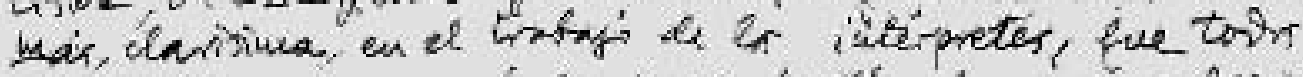

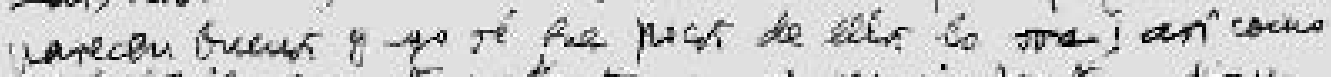

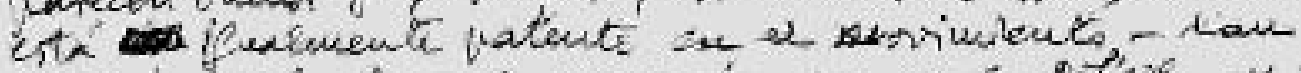

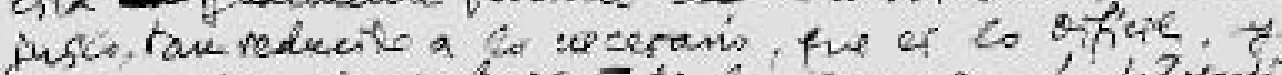

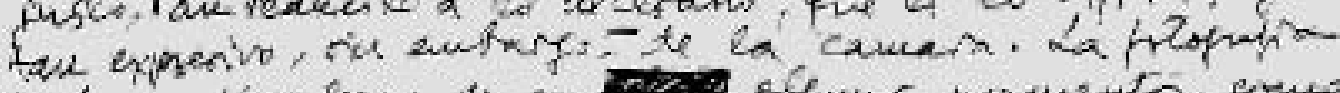

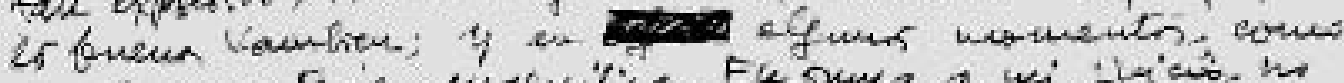

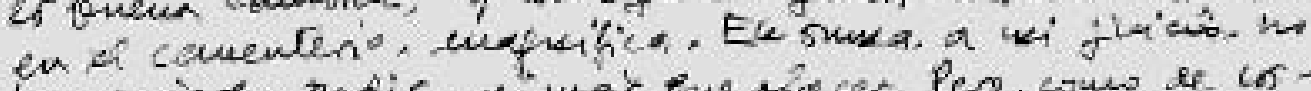

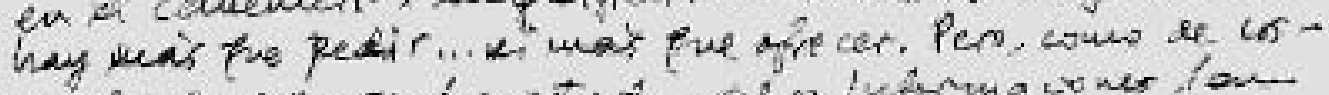

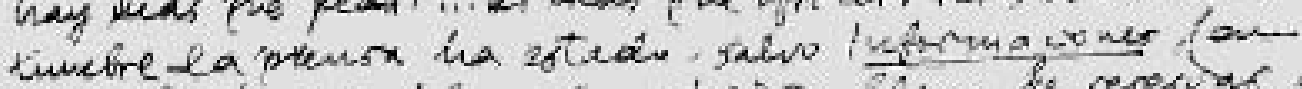

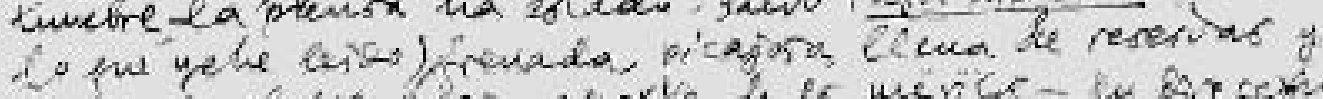

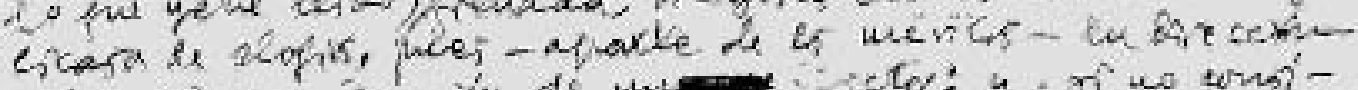

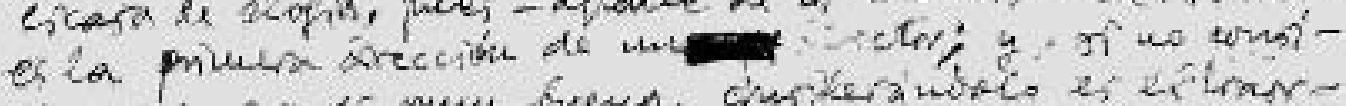

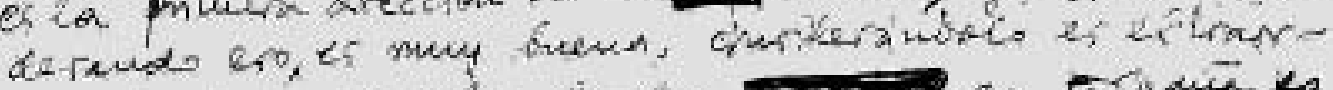

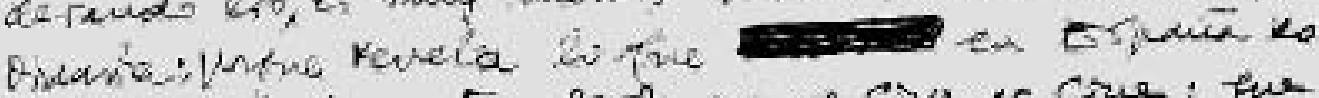

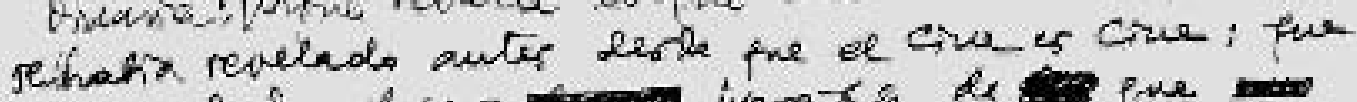

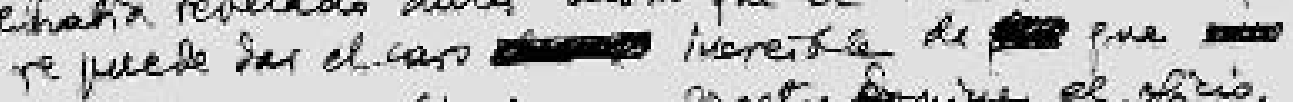

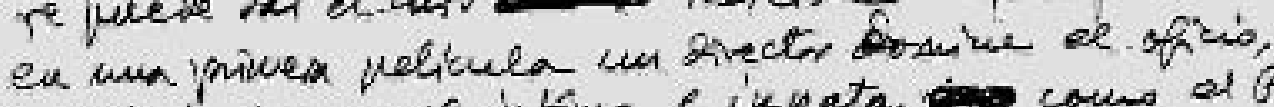

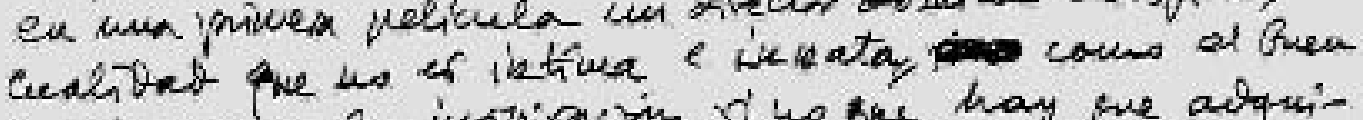

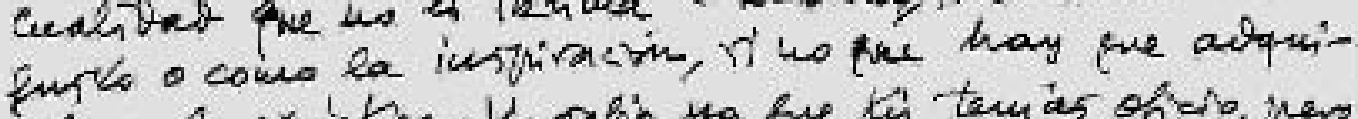

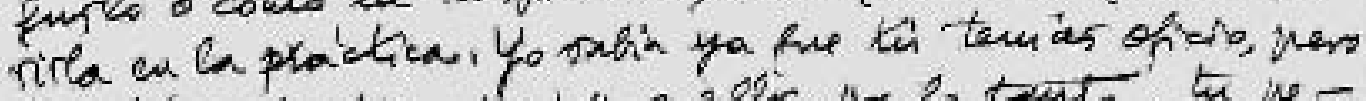

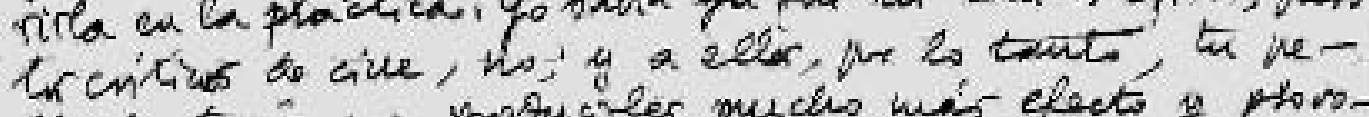

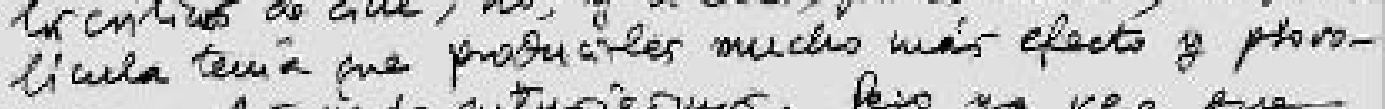

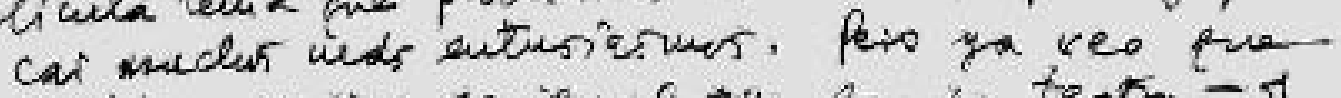

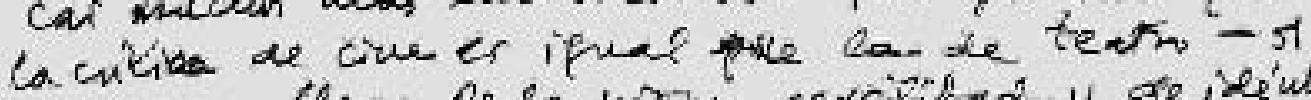

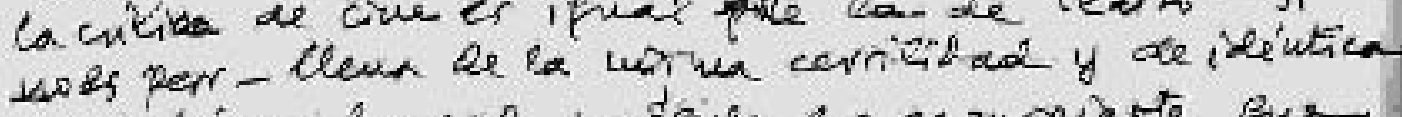

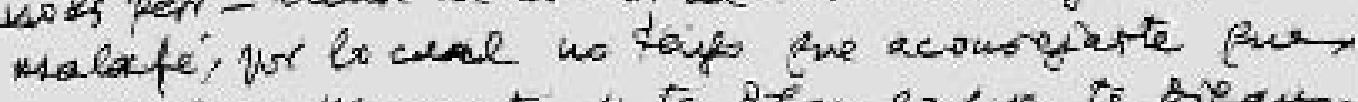

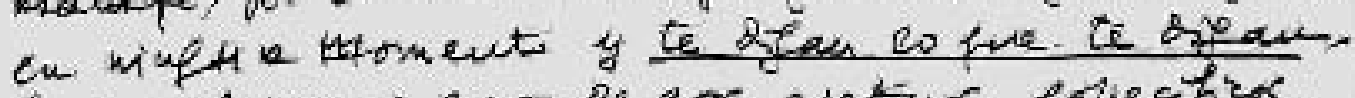
hatar al weur caro Re aros creturos enfecifiers, iveapacer de estivury nada wi de proclawer ne

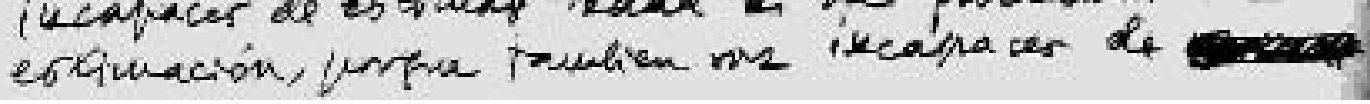

doi: 10.3989/arbor.2011.748n2009

ARBOR Vol. 187748 marzo-abril [2011] 287-303 ISSN: 0210-1963

299 
3.

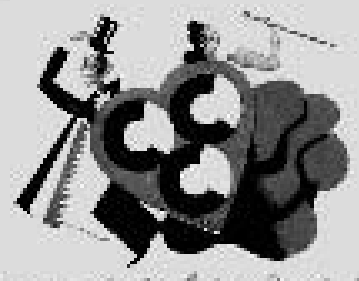

\section{EARIUUE IARUIEL PO\CEIA}

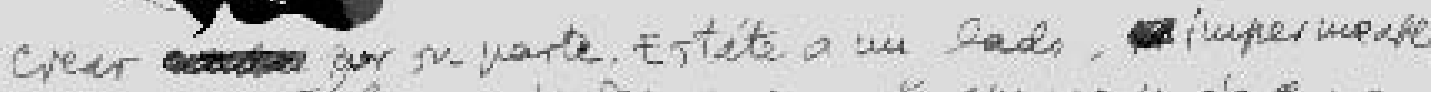

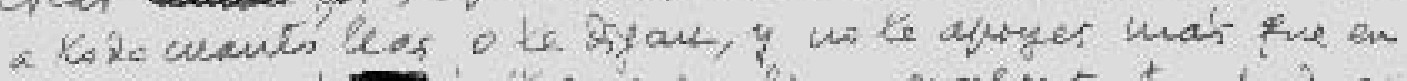

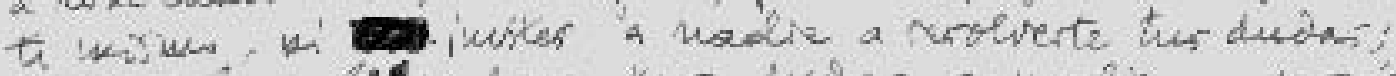

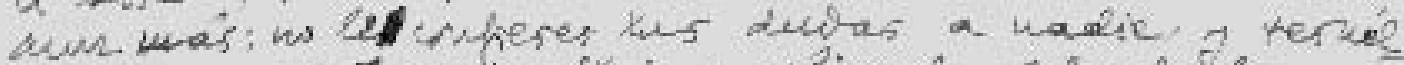

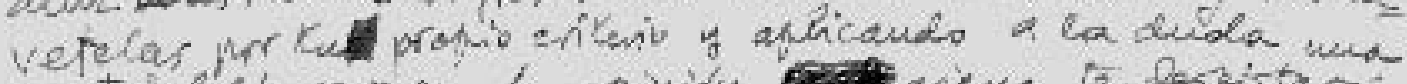

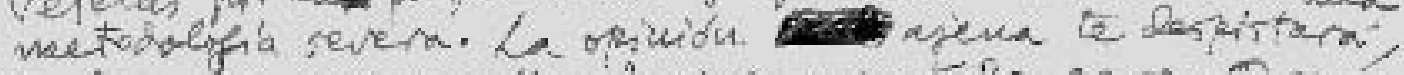

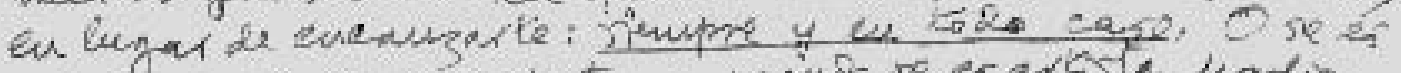
cilista o w re es arista y duaud re es arista kadie

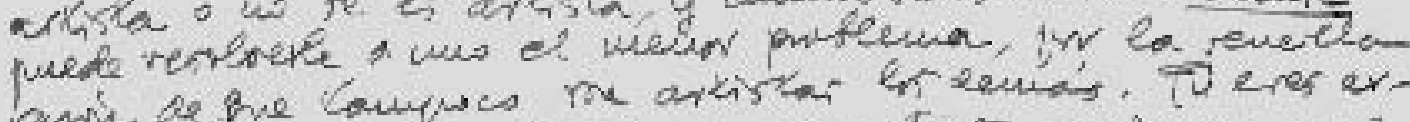

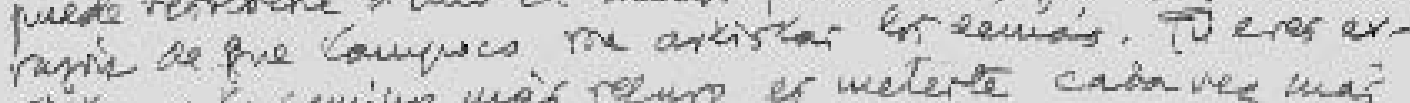

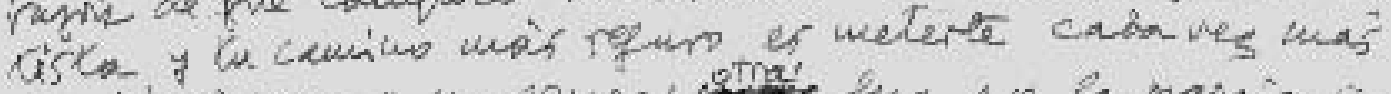

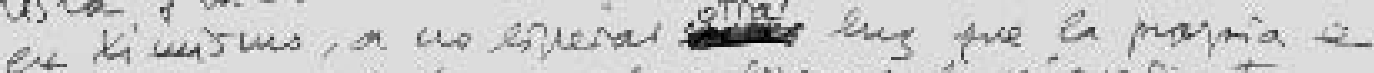

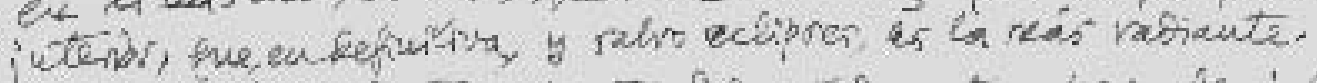

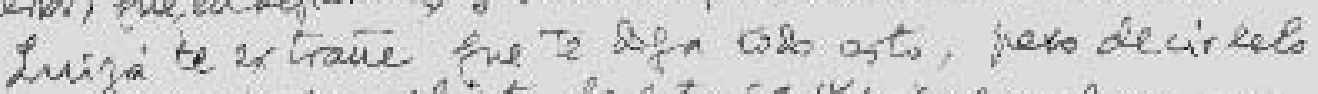

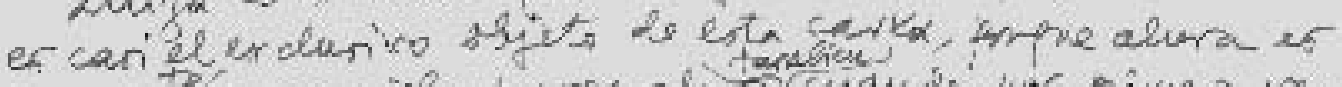

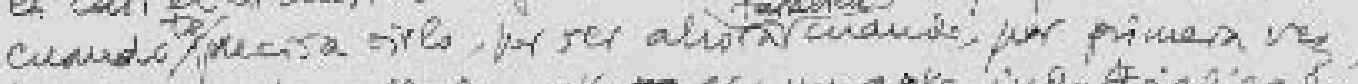

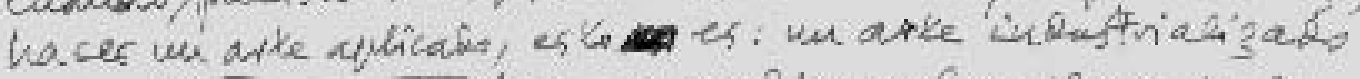

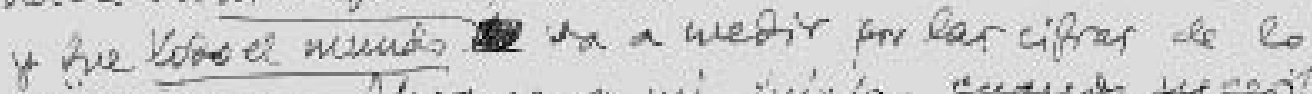

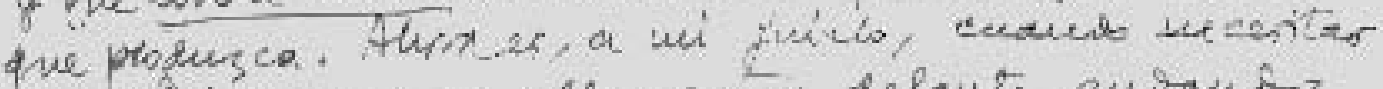

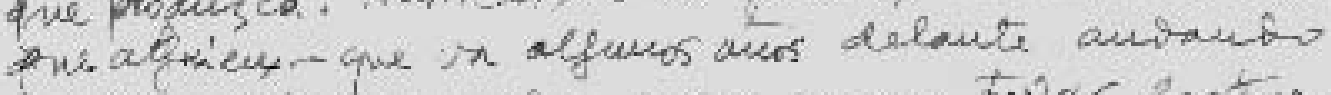

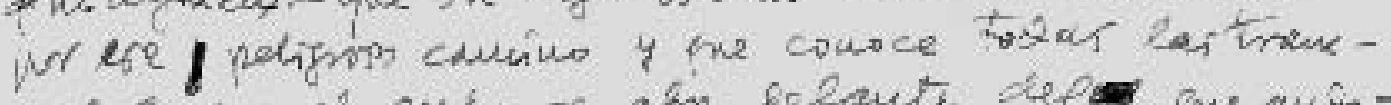

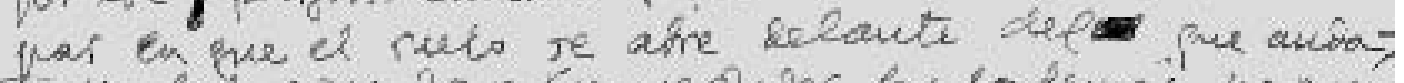

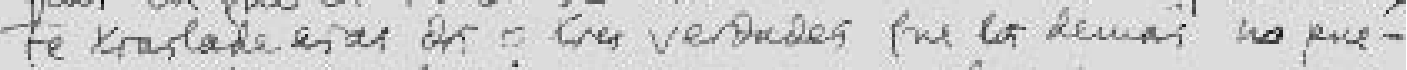

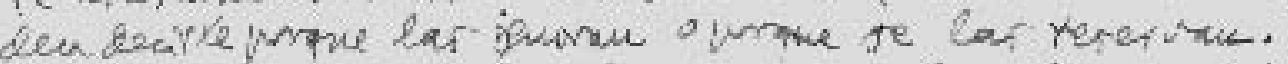

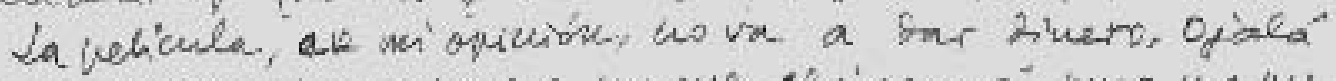

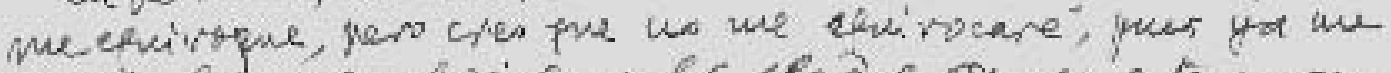

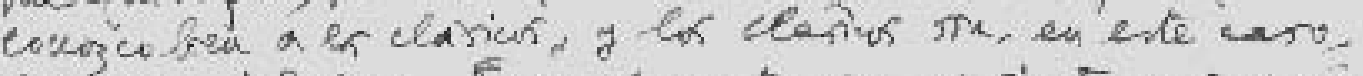

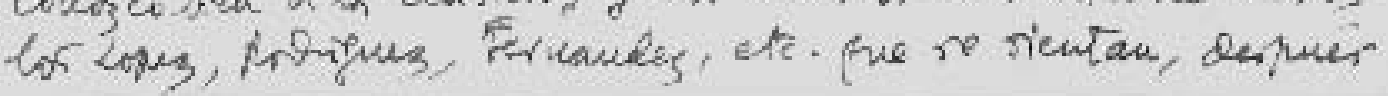




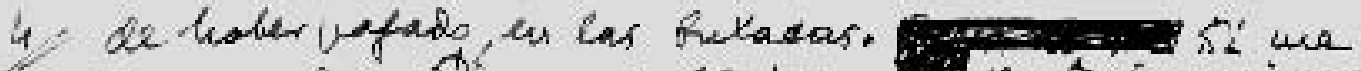
efuivoco, nada. Th wo we efuivocon bo tedermives

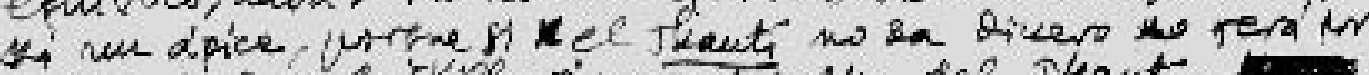
culpa de Ruin. Cankitelo, xi un hor culpe del Thant,

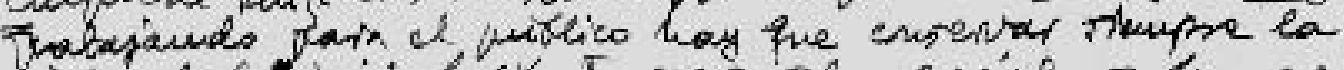

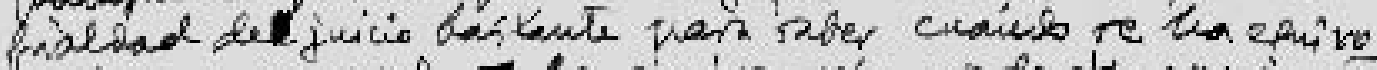

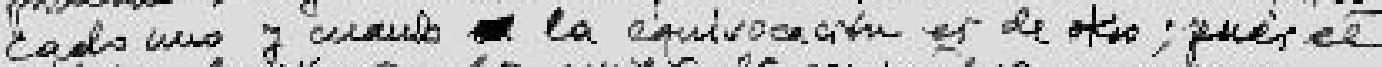

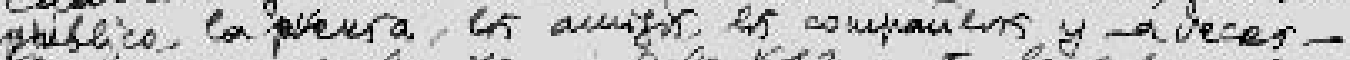

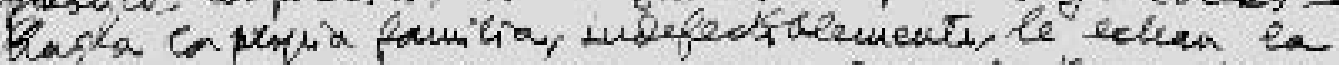

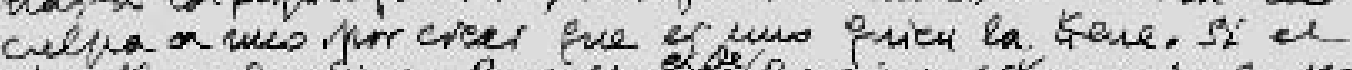

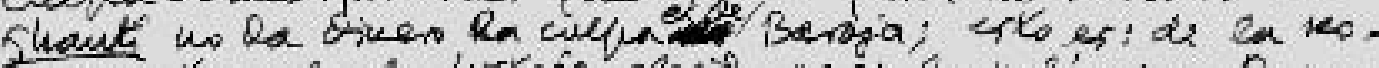

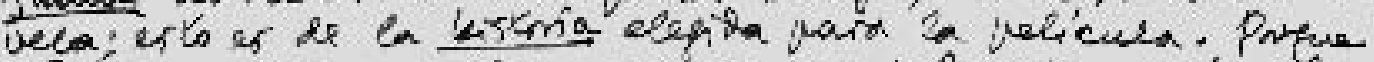

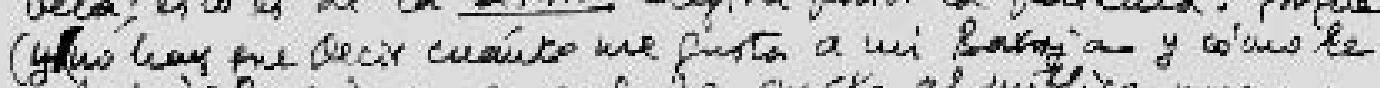

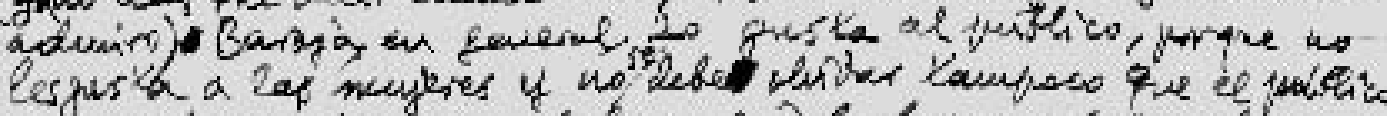

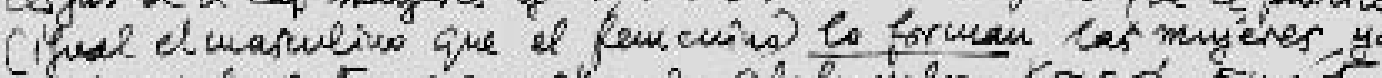

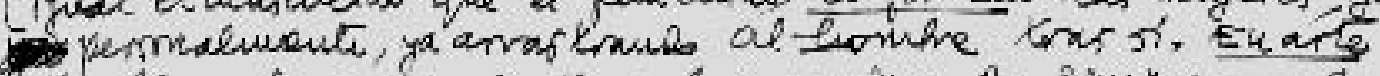

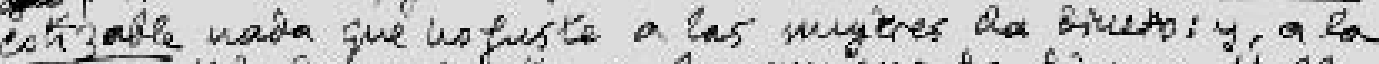

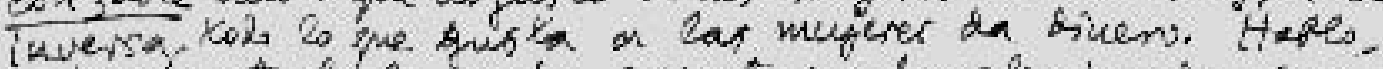

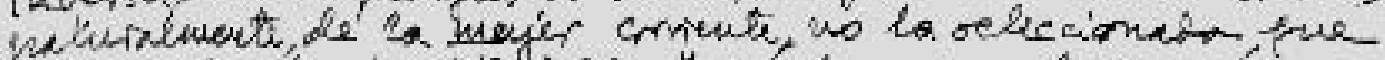

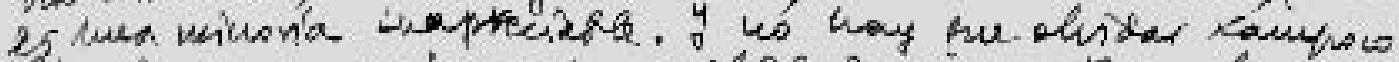
2.

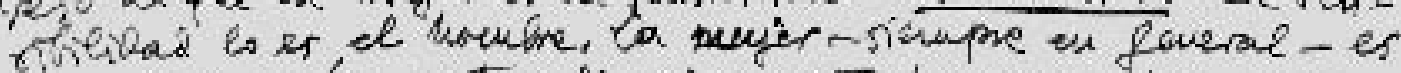

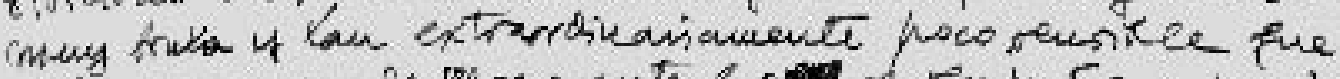

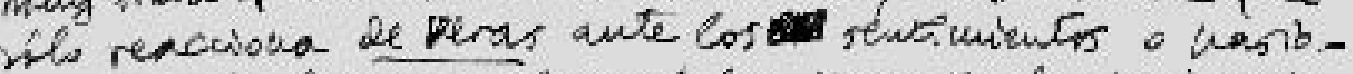

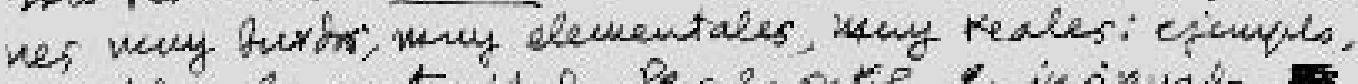

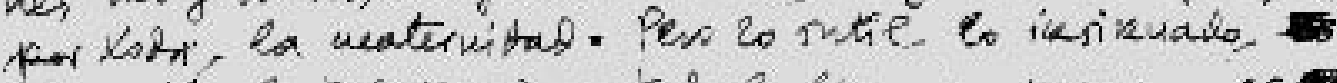

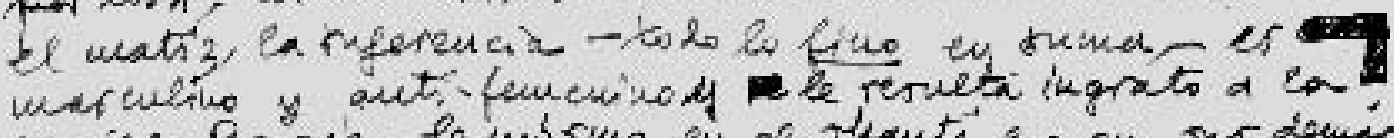

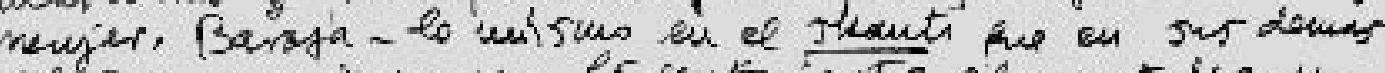

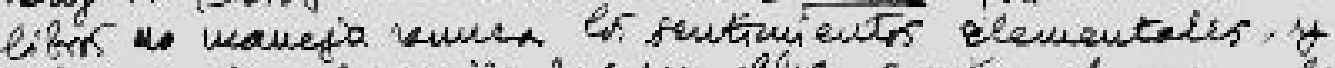

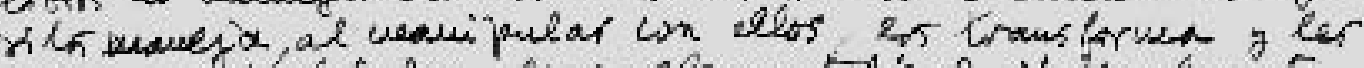

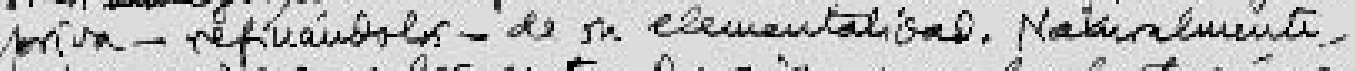

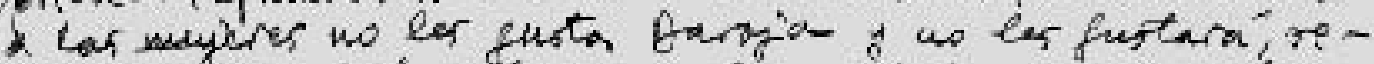
turauente el thant, en el ine ki bar conservado,

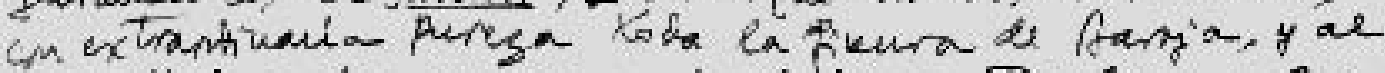

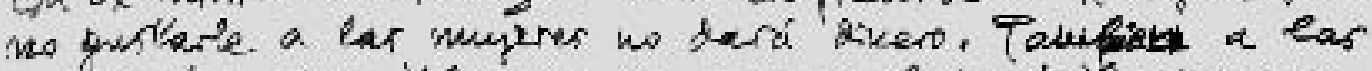

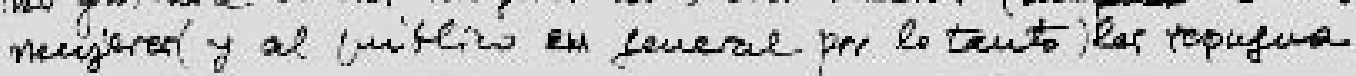


5.

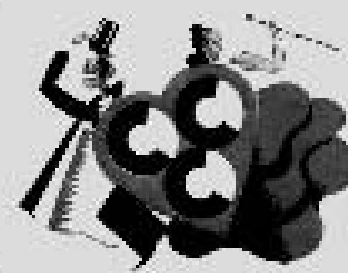

\section{EVRIOUE , IARIJIEL PONCEIA}

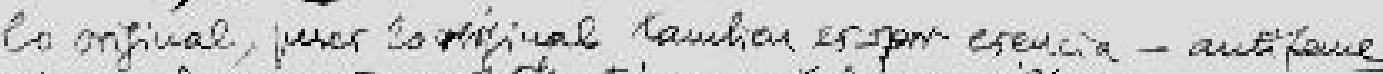

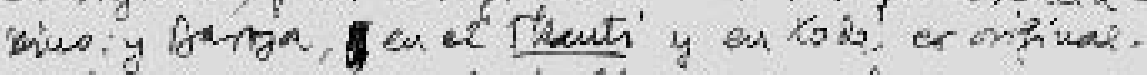

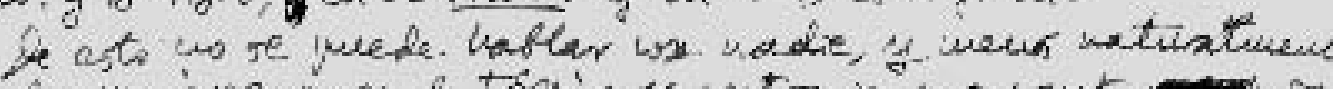

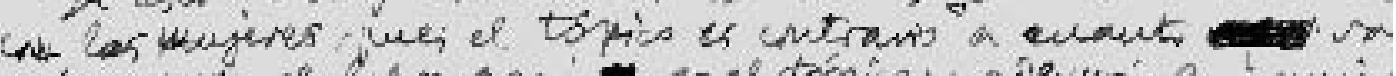

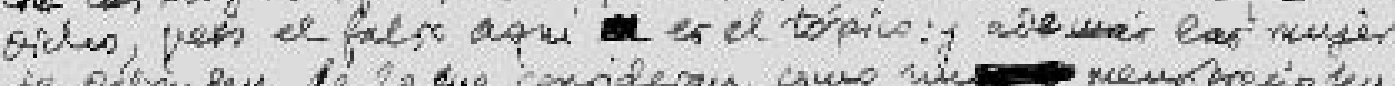

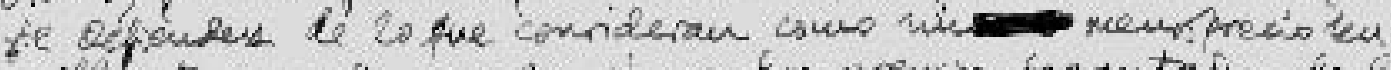

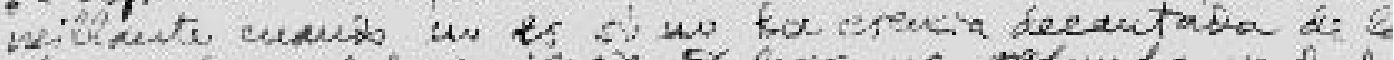

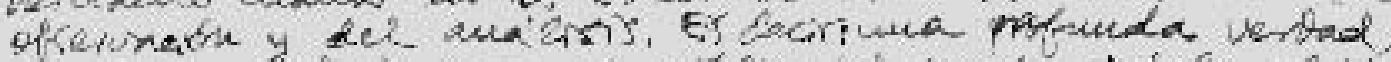

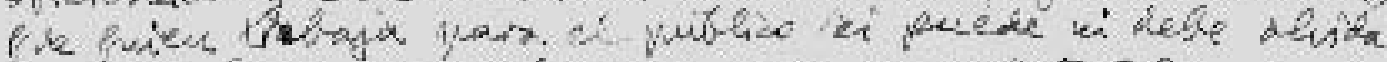

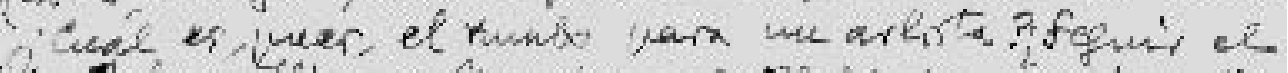

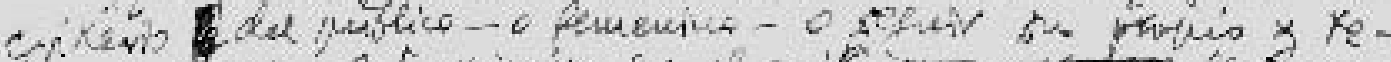

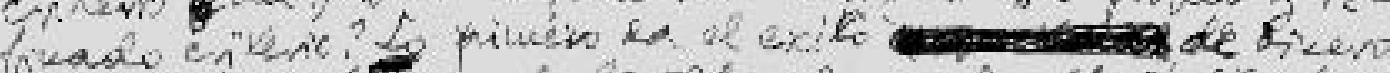

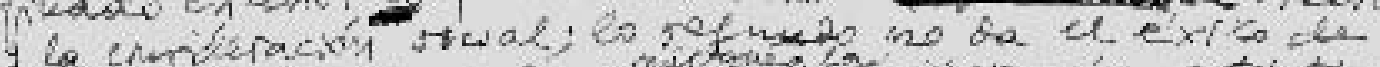

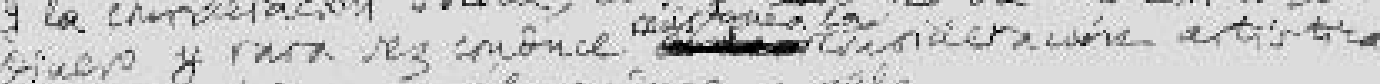

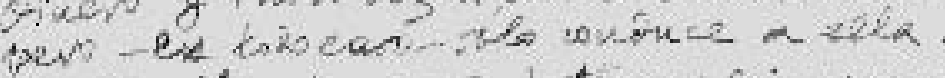

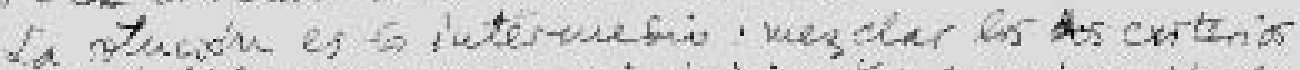

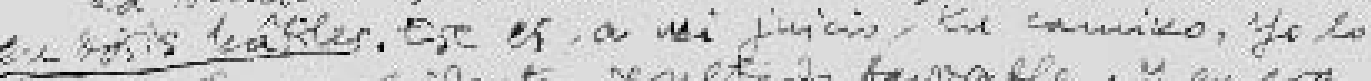

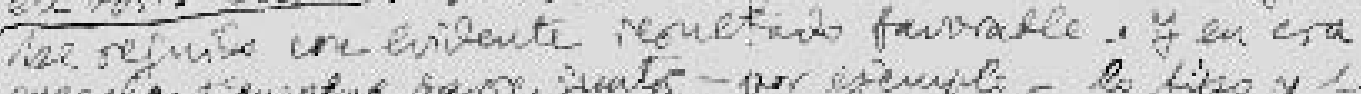

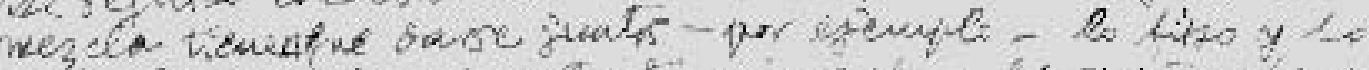

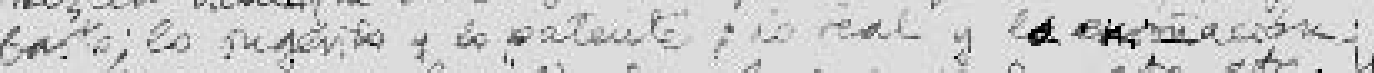

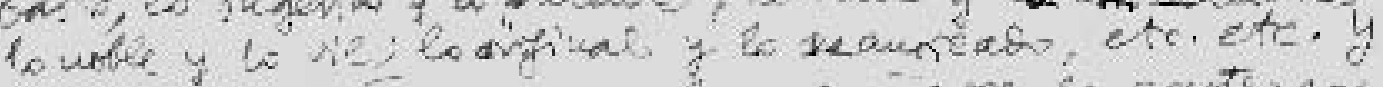

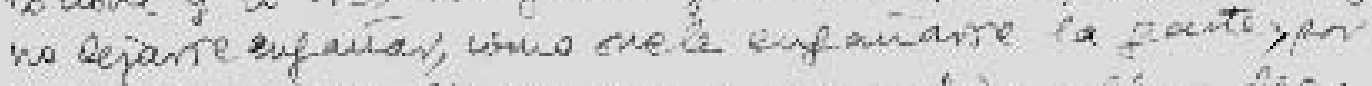

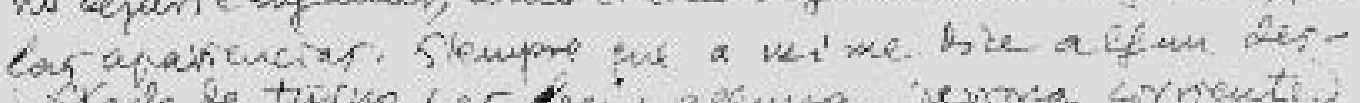

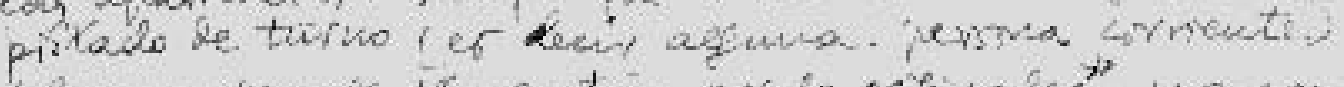

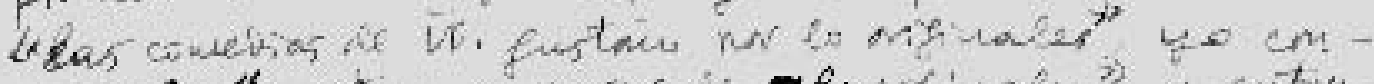

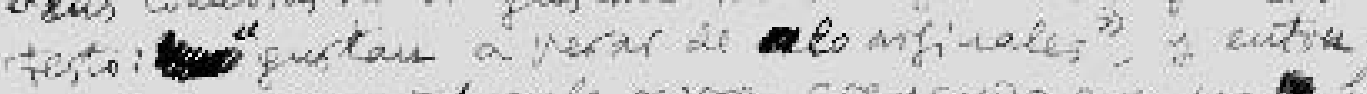

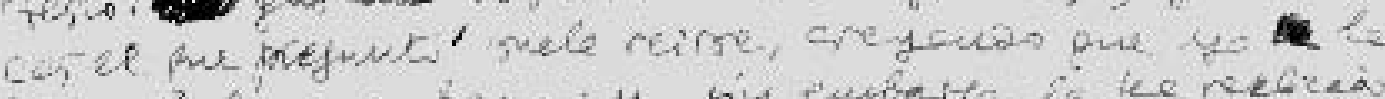

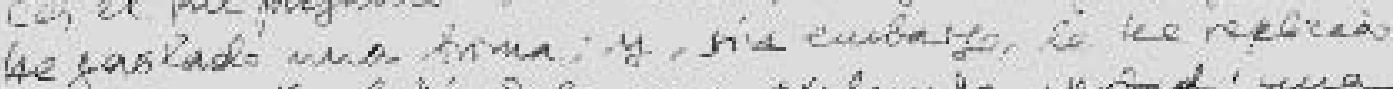

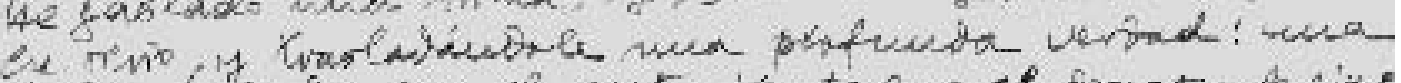

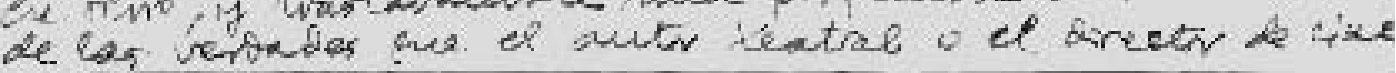




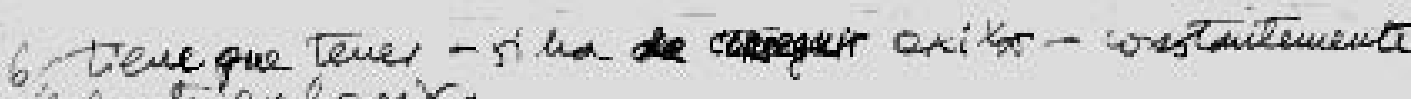
deraute ex lo ajos.

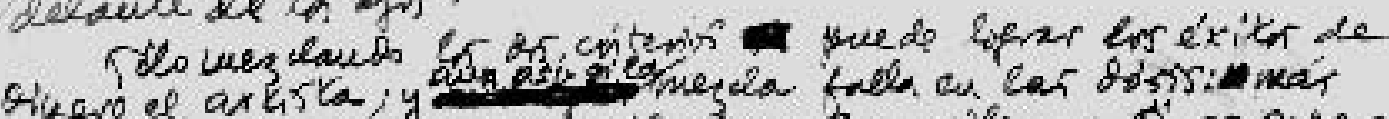

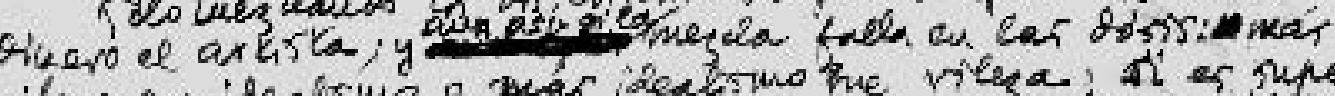

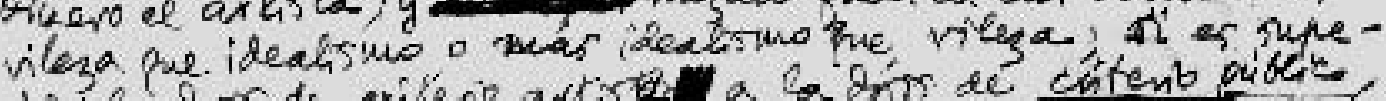

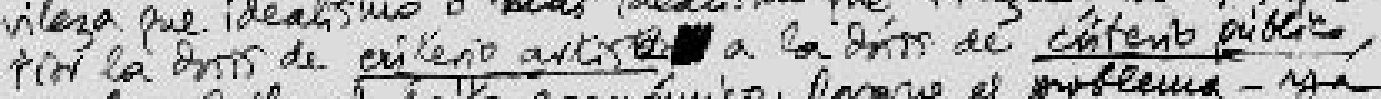

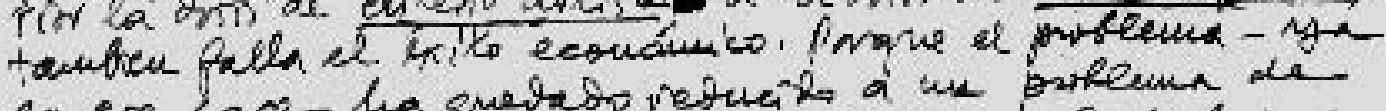

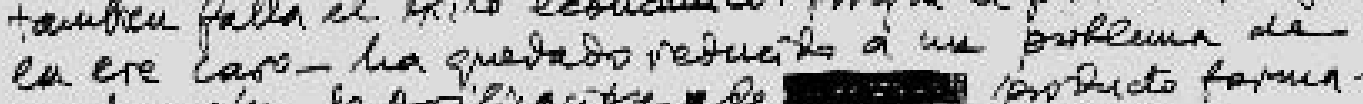

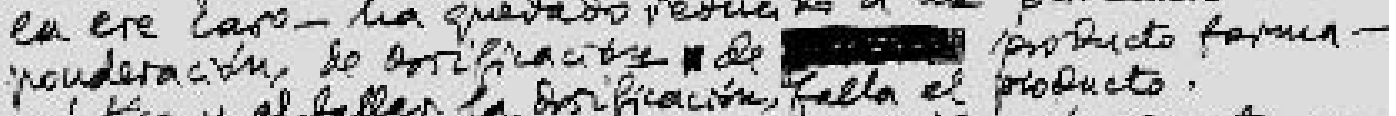
cét tico of el faller fa sorificación, fella el prooucto.

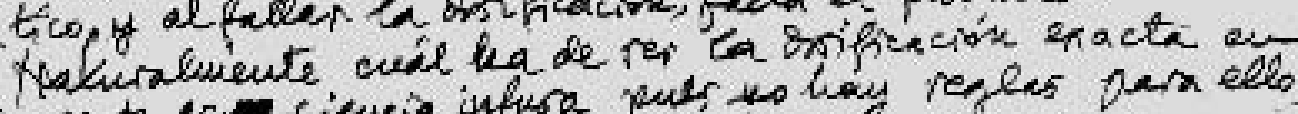

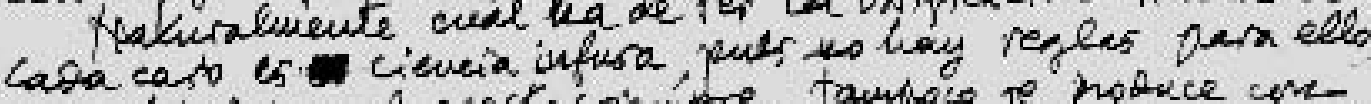
y de ali el the el acertar sienure tauposo te poonce comla weucion.ta firmula do wejela do bo in criteris, pero

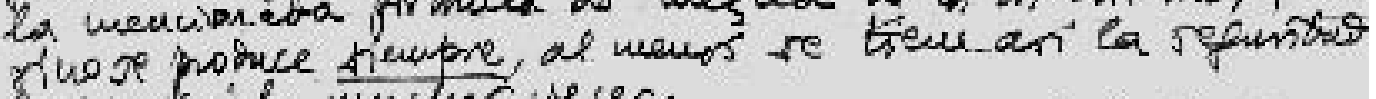
de conscluirlo wuscers veces.

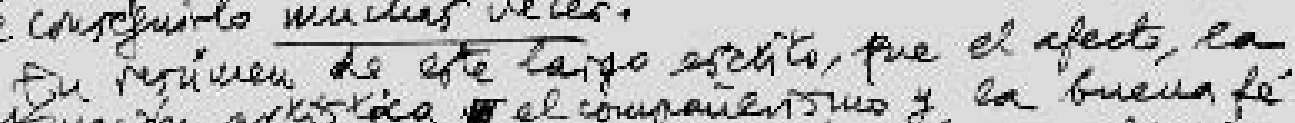

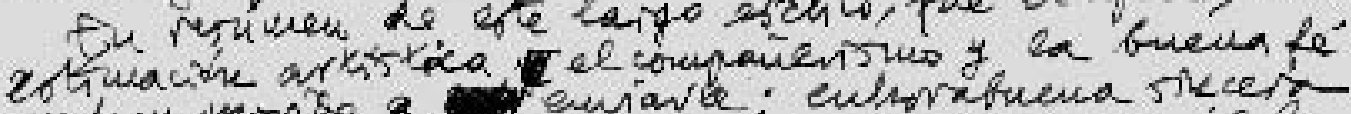

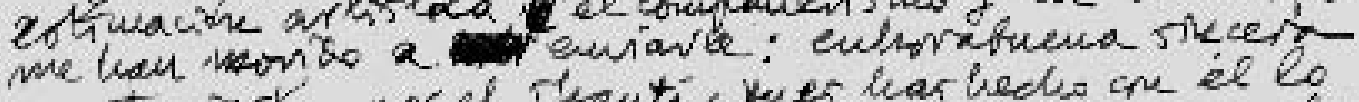

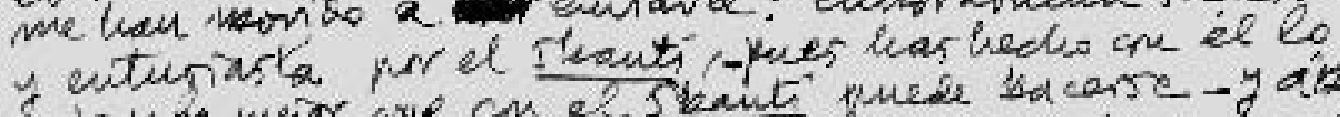

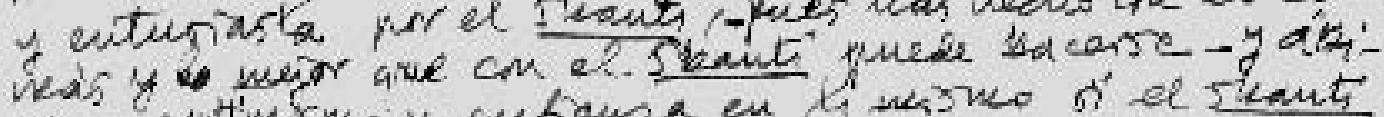

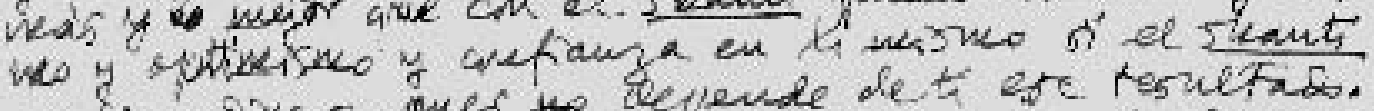

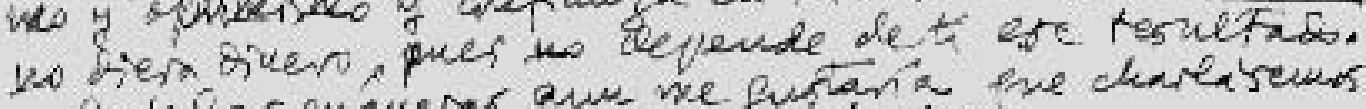
Ve tovar maveras aw me gurtania ine chareabewas theif ribubrera ocarish. ya le hatis:

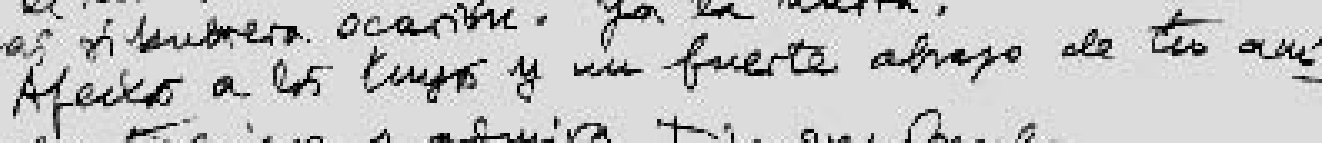

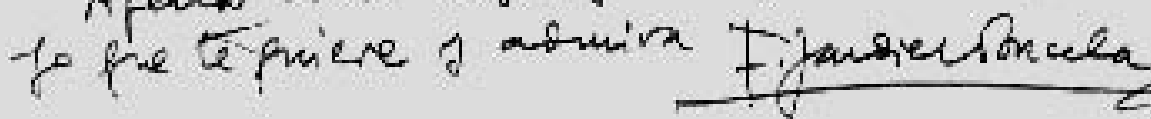

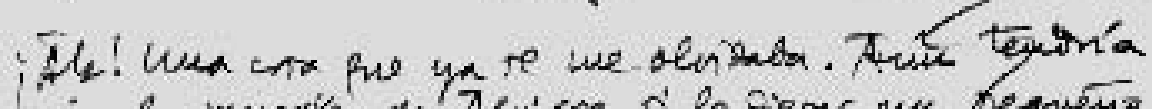

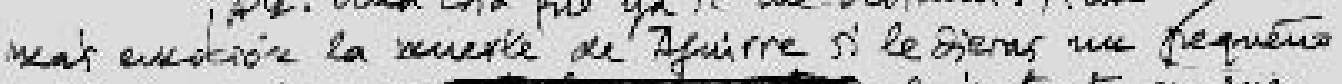

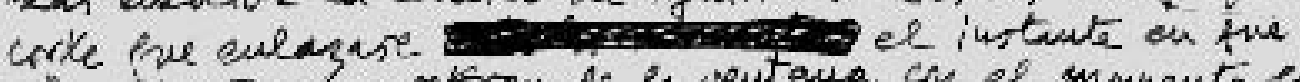
Thanth y piary re retran de la venteva cre el mounto en

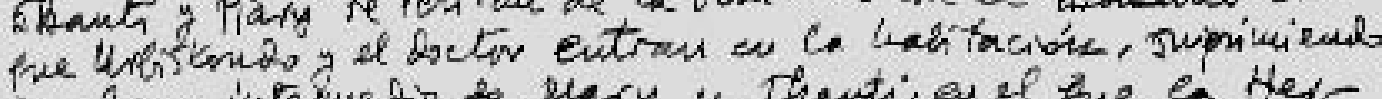

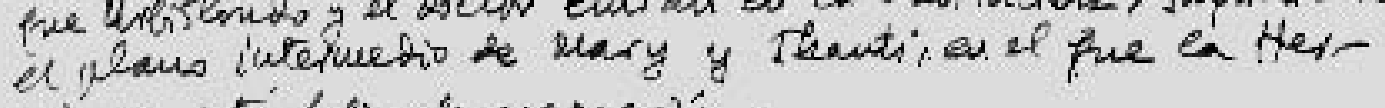
vau no esta feliz de expresise.

Tone do del bave er axpleintio.

doi: 10.3989/arbor.2011.748n2009

ARBOR Vol. 187748 marzo-abril [2011] 287-303 ISSN: 0210-1963

303 